\title{
Recent advances on InAs/InP quantum dash based semiconductor lasers and optical amplifiers operating at $1.55 \mu \mathrm{m}$
}

\author{
F. Lelarge, B. Dagens, J. Renaudier, R. Brenot, A. Accard, F. van Dijk, D. Make, O. Le Gouezigou, J.-G. Provost, F. \\ Poingt, J. Landreau, O. Drisse, E. Derouin, B. Rousseau, F. Pommereau, and G-H. Duan, Senior Member, IEEE
}

Alcatel Thales III-V Lab, Route Départementale 128, 91767 Palaiseau, France

Invited Paper

\begin{abstract}
This paper summarizes recent advances on InAs/InP quantum dashes (QD) materials for lasers and amplifiers, and QD device performance with particular interest for optical communication. We investigate both InAs/InP dashes in a barrier and dashes in a well (DWELL) heterostructures operating at $1.5 \mu \mathrm{m}$. These two types of QDs can provide high gain and low losses. Continuous-wave room-temperature lasing operation on ground state of cavity length as short as $200 \mu \mathrm{m}$ has been achieved, demonstrating the high modal gain of the active core. A threshold current density as low as $110 \mathrm{~A} / \mathrm{cm}^{2}$ per QD layer has been obtained for infinite-length DWELL laser. An optimized DWELL structure allows achieving of a $\mathrm{T}_{0}$ larger than $100 \mathrm{~K}$ for broad area lasers and of $80 \mathrm{~K}$ for single transverse mode lasers in the temperature range between $25^{\circ} \mathrm{C}$ and $85^{\circ} \mathrm{C}$. Buried ridge stripe type single mode DFB lasers are also demonstrated for the first time, exhibiting a side-mode suppression-ratio as high as $45 \mathrm{~dB}$. Such DFB lasers allow the first floor free $10 \mathrm{~Gb} / \mathrm{s}$ direct modulation for back-to-back and transmission over $16 \mathrm{~km}$ standard optical fiber. In addition, novel results are given on gain, noise and four wave mixing of QD-based semiconductor optical amplifiers. Furthermore, we demonstrate that QD FP lasers, owing to the small confinement factor and the 3D quantification of electronic energy levels, exhibit a beating linewidth as narrow as $15 \mathrm{kHz}$. Such an extremely narrow linewidth, compared to their QW or bulk counterparts, leads to the excellent phase noise and time jitter characteristics when QD lasers are actively mode-locked. These advances constitute a new step towards the application of QD lasers and amplifiers to the field of optical fiber communications.
\end{abstract}

Keywords: quantum dots, semiconductor lasers, semiconductor optical amplifiers, mode-locked laser, clock recovery 


\section{INTRODUCTION}

High performance, reliable and low-cost semiconductor lasers and semiconductor optical amplifiers (SOA) are crucial for applications in optical communications, optical interconnects or microwave/millimeter wave transmission over optical fibers. During the past years, self-assembled semiconductor quantum dot/quantum dash (QD) devices have attracted considerable attention due to the unprecedented potential offered by the 3D energy levels quantification. Indeed, QD lasers are expected to present lower threshold current, lower chirp, higher gain, and higher thermal stability than quantum well (QW) or bulk based devices (see for instance [1] and references herein). QD based SOAs are also expected to present reduced noise figure and fast dynamic response. Besides, QD mode-locked lasers are attractive because of the fast carrier dynamics and the broad gain spectrum provided by these new material structures.

Today, QD devices based on InAs/GaAs system operating in the $1.3 \mu \mathrm{m}$ window achieve a relative maturity with already demonstrated outstanding performances such as high $\mathrm{T}_{0}$, high differential gain, etc [1, 2, 3, 4]. QD lasers based on InAs/InP are of great interest as they operate at the most interesting telecom window (1.4-1.6 $\mu \mathrm{m})$. Compared to InAs/GaAs QD materials, the growth of isotropic dots based on InAs/InP (100) materials is much more difficult. Two approaches are currently developped: the former one consists in using (311)B surface [5,6], the latter one is based on the optimization of quantum dash on (100) oriented substrates. In the following, we will focus on the second one, which allows using the fabrication process developed so far for QW or bulk devices. Using such an approach, continuous wave (CW) room-temperature lasing operation has been achieved on InP (001) substrate with quantum-dashes grown within InGaAlAs quantum well structures [7], and with QD structures including InGaAlAs barriers [8, 9], or InGaAsP barriers $[10,11]$. More recent realizations demonstrate improved temperature stability with p-doping or tunnel injection laser structures $[12,13,14,15,16]$. Despite such progress on InAs/InP based QD structures, there are still several challenges to overcome before real system applications for these components.

The first challenge is to achieve high gain allowing low threshold current density of QD lasers. A single quantum dot has very small dimensions, leading to very small interaction between optical modes and the single QD. It is thus essential to be able to grow high quality QD with sufficient dots density and to master the stacking of QD layers. Another important issue is to allow a good coupling between the 3D electronic sates and the QD electronic state in order to allow efficient capture of electrons into QD. This paper will report on 2 types of QD structures: dashes in a barrier and dashes in a well (DWELL). CW room-temperature lasing operation of short cavity length is achieved on InP (001) substrate with both structures. A threshold current density as low as $110 \mathrm{~A} / \mathrm{cm}^{2}$ per QD layer is achieved for infinite length DWELL laser. The high gain of such a QD-based structure allows lasing on ground state even for very short cavity length, contrary to the $1.3 \mu \mathrm{m}$ InAs/GaAs system.

The second challenge is to obtain high $\mathrm{T}_{0}$ leading to temperature insensitivity for uncooled operation. There are several ways to improve $\mathrm{T}_{0}$ : optimization of epitaxial layers, p-doping [12-14], and tunnel injection [15, 16]. In the paper, we report on novel temperature sensitivity results for both p-doping and optimized DWELL structures. We 
demonstrate that an optimized DWELL structure can achieve $\mathrm{T}_{0}$ higher than $100 \mathrm{~K}$ for broad area (BA) lasers and $80 \mathrm{~K}$ for single transverse mode lasers in the $25^{\circ} \mathrm{C}-85^{\circ} \mathrm{C}$ temperature range. It is worth noting that such high $\mathrm{T}_{0}$ is achieved without degrading the threshold current. For instance, a single mode $600 \mu \mathrm{m}$-long FP laser can operate up to $85^{\circ} \mathrm{C}$ with a threshold current as low as $25 \mathrm{~mA}$.

The third challenge is to demonstrate the ability of these lasers to be modulated at high bit-rate with low chirp for optical fiber transmission. We report for the first time on the realisation of buried ridge stripe (BRS) type single mode DFB lasers, exhibiting a side-mode suppression-ratio (SMSR) as high as $45 \mathrm{~dB}$. The first floor free $10 \mathrm{~Gb} / \mathrm{s}$ direct modulation is demonstrated for back-to-back, as well as transmission over $16 \mathrm{~km}$ on standard optical fibers. Whereas optimization has still to be done in order to further increase the global electrical modulation bandwidth, this first buried DFB DWELL laser operating at $10 \mathrm{~Gb} / \mathrm{s}$ in the $1.55 \mu \mathrm{m}$ range demonstrates the high potentiality of this kind of structures as optical sources for telecommunication.

The fourth challenge is to fabricate SOAs with large amplification gain and low noise for optical amplification. This paper will describe the results on gain and noise in QD SOAs and reports on novel results on four-wave-mixing in these devices.

The final challenge is to address the generation of low jitter pulses in mode-locked lasers. Such sources are of particular interest for high repetition rate sources, all-optical clock recovery and microwave applications. Passive modelocking has already been reported at $1.3 \mu \mathrm{m}$ using GaAs based QD [17, 18, 19], and also at $1.5 \mu \mathrm{m}$ using InP based materials with either quantum wells or bulk type active layers [20, 21]. In this paper, we describe the passive modelocking in Fabry-Perot (FP) cavity QD lasers. [22,23,24,25,26] We demonstrate that the QD FP lasers, owing to the small confinement factor and the 3D quantification of electronic energy level, exhibit a beating linewidth as narrow as 15 $\mathrm{kHz}$. Such an extremely narrow linewidth, compared to their QW or bulk counterparts, leads to the excellent phase noise and time jitter characteristics when QD lasers are actively mode-locked.

This paper will summarize all these state-of-the-art advances on quantum dash based semiconductor lasers using InAs/InP at the $1.55 \mu \mathrm{m}$ window. These lasers achieve such a degree of maturity that the performance becomes comparable or even surperior to that of MQWs devices. The paper is organized as follows: Section II will be devoted to present the main characteristics of the InAs/InP quantum dash material. Section III will be focused on the continuous wave operation of QD lasers, including material gain, optical losses and temperature sensitivity. Section IV will describe single-transverse mode DFB lasers performance, including both dynamic and noise performance of QD laser. Section V will be focused on SOAs including optical gain and noise performance. Section VI will be dedicated to mode-locked lasers and their QD induced disruptive properties. A conclusion will be drawn at the end of the paper. 


\section{QUANTUM DOT MATERIAL FABRICATION AND CHARACTERIZATION}

The device performance of QD-based heterostructures depends strongly on how the carriers are confined in the nanostructures. It is therefore essential to get an accurate control of the shape of such nanostructures in the 3 directions. In our study, the QD-based heterostructures were grown by GSMBE on S-doped (100) InP wafers, using the "selforganized" Stransky-Krastanow growth mode. Its principle is based on strain relaxation occurring in a very thin $(\sim 1 \mathrm{~nm})$ highly-strained InAs layer deposited on an InGaAsP layer. The mismatch between the material lattice constants, of typically $4 \%$ in this material system, induces the QDs formation. Using standard GSMBE growth conditions and due to the weak driving force for the QDs formation on (001) InP, the "self-organization" remains highly sensitive to the GaInAsP surface anisotropy, leading to the formation of nanostructures elongated along the [1-10] direction. Figure 1 shows an example of transmission electron microscopy (TEM) plan-view image of such a QD structure. The dimension along the growth axis, which is controlled by the nominal thickness of the InAs layer to achieve $1.55 \mu \mathrm{m}$ emission, is about $2 \mathrm{~nm}$. The typical width of the dashes is about $15-20 \mathrm{~nm}$. The length of the dashes depends on the growth conditions, ranging between 40nm and 300nm. As a consequence, the surface density of QDs is ranging between 1 and $4.10^{10} \mathrm{~cm}^{-2}$. All the devices studied here are based on such elongated dots.

Figure 2 describes schematically the two types of active layer structure studied in this paper. The first one, called dashes in a barrier, consists of InAs QDs enclosed within 40nm-thick barriers and two 80nm-thick separate confinement heterostructure $(\mathrm{SCH})$ layers. Both barriers and $\mathrm{SCH}$ are undoped and lattice-matched quaternary $\mathrm{Ga}_{0.2} \mathrm{In}_{0.8} \mathrm{As}_{0.4} \mathrm{P}_{0.6}$ layers $(\lambda \mathrm{g}=1.17 \mu \mathrm{m})$. In the second structure, called DWELL, the QDs are in addition embedded within 8nm-thick quantum wells (QWs) obtained from lattice-matched quaternary material emitting at $1.45 \mu \mathrm{m}$. The barrier for QW is again the quaternary $\mathrm{Ga}_{0.2} \mathrm{In}_{0.8} \mathrm{As}_{0.4} \mathrm{P}_{0.6}$ material with $\lambda \mathrm{g}=1.17 \mu \mathrm{m}$. Both QDs in a barrier and DWELL structures are designed to allow light emission within the 1.5-1.6 $\mu \mathrm{m}$ range.

By taking into account the QDs thickness and lateral dimensions, the optical confinement factor is estimated to be as small as $0.15 \%$ per QDs layer in a typical single transverse mode laser structure. Such a low value is to be compared with $\sim 1 \%$ per well in QW structures. It is thus crucial to stack QDs layers to achieve sufficient modal gain. However, the stacking of QD layers is accompanied by changes in density and dimensions of the nanostructures, leading to larger QDs size distribution. Such a phenomenon is evidenced by the broadening of photoluminescence spectra, and therefore leading to a reduced modal gain for a given wavelength bandwidth. It is consequently required to study not only the shape of the nanostructures in the growth plane, but also the influence of the stacking of successive QDs layers.

Figure 3 shows a cross-sectional TEM image of a stack of 3 nominally identical QDs layers. As illustrated in this figure, the QDs are aligned along the growth axis but one can see the significant increase of QDs thickness with the stacking. It is to be noted that the strong interaction between successive QDs layers is related to the strain field that propagates across the barriers. This strain field has a strong impact on the barrier growth, as demonstrated by the surface roughness after the burying of the last QD layer. It modifies the chemical potential of the growth surface, leading to 
preferential seeding of QDs on top of buried QDs. This effect increases when the spacer barrier is reduced below 60nm, which clearly limits the stacking of closely spaced QDs layers.

A solution has been developed to overcome this stacking limitation. It consists in reducing the nominal thickness of subsequent QDs layers in order to compensate for the natural thickening of QDs during the stacking. We therefore use an empiric rule that involves growth conditions, number of QDs layers, thickness and strain of barriers. Such a rule enables us to fabricate stacks with up to 12 QDs layers. The first criteria to validate this approach is to check if the full width at half maximum (FWHM) of photoluminescence (PL) spectra remains constant as the stack number increases. Figure 4 shows the variation of the FWHM with the number of QDs layers. We observe that the achieved PL linewidth for 1, 3, 6, 9 and 12 QDs layers is about $68,68,70,73$ and $89 \mathrm{meV}$, respectively. Such a weak dependence of the PL FWHM on the number of stacked QDs layers demonstrates that an efficient control is achieved at least up to 9 QDs layers. A typical PL spectrum of a DWELL laser active core comprising 6 QDs layers is shown in figure 5. The QDs emission (1.56 $\mu \mathrm{m})$ is clearly dominant. Neither wetting layer emission nor excited transitions are visible. The emission at $1.17 \mu \mathrm{m}$ comes from the grating layer included on top of the active layer for DFB processing.

\section{CONTINUOUS-WAVE CHARACTERISTICS OF QD SEMICONDUCTOR LASERS}

\subsection{Gain, losses and CW characteristics}

BA and BRS lasers were processed using our standard technological steps established for InGaAsP MQWs lasers. For BA lasers, p-doped InP cladding layer and GaInAs contact layer are grown using metal organic vapor phase epitaxy (MOVPE). 50 $\mu \mathrm{m}$-wide contacts are defined by lift-off lithography. For BRS FP lasers, ridge wave-guides with widths from 1 to $3 \mu \mathrm{m}$ are defined in a photoresist layer using contact lithography. The pattern is transferred into a dielectric layer and then into the InP-based material. P-doped InP cladding layer and GaInAs contact layer are grown using MOVPE. Lateral localization of carriers is obtained by proton implantation. $\mathrm{P}$ and $\mathrm{N}$ electrical contact pads are realized by ion beam sputtering of Ti/Pt/Au. It is to be noted that the growth of QDs over (100) oriented substrates allows to use the fabrication process developed so far for QW or bulk components.

Fig. 6 shows the threshold current density as a function of the reciprocal length of BA lasers with 6 QDs layers for both dots in a barrier and DWELL structures. It is worth noting that Fig. 6 includes results of long-cavity devices $(>1000 \mu \mathrm{m})$, allowing an accurate determination of threshold current density for infinite-length cavity. From the dependence of laser threshold current density versus cavity length on a large range of cavity length (175-3000 $\mu \mathrm{m})$, we derive a threshold current density for infinite length of $1.14 \mathrm{kA} / \mathrm{cm}^{2}$, which corresponds to about $190 \mathrm{~A} / \mathrm{cm}^{2}$ per dash layer. By inserting the QDs layer within a quantum well, the threshold current density for infinite length is reduced down to $0.66 \mathrm{kA} / \mathrm{cm}^{2}\left(110 \mathrm{~A} / \mathrm{cm}^{2}\right.$ per dash layer $)$, likely due to a better carrier injection.

In Fig. 7, the reciprocal external differential efficiency is depicted as a function of cavity length for a DWELL 
laser comprising 6 dash layers. It is well-known that the external efficiency $\eta_{\text {ext }}$ for a FP laser is given by [27]:

$$
\eta_{\text {ext }}=\eta_{\text {in }} \frac{\alpha_{m}}{\alpha_{\text {in }}+\alpha_{m}}
$$

where $\eta_{\text {in }}$ is the internal efficiency, $\alpha_{\text {in }}$ the internal material losses and $\alpha_{m}$ the miror losses given by [27]:

$$
\alpha_{m}=\frac{1}{2 L} \log \left(\frac{1}{R_{1} R_{2}}\right)
$$

where $L$ is the cavity length, $R_{1}$ and $R_{2}$ are the facet reflectivities.

From the linear fit of laser reciprocal external efficiency for cavity lengths between 300 and $1900 \mu \mathrm{m}$, we derive an internal efficiency of $0.65 \mathrm{~W} / \mathrm{A}$, corresponding to an internal quantum efficiency $\sim 80 \%$. The internal losses are estimated to be about $19 \mathrm{~cm}^{-1}$. As can be seen from Fig.6, room temperature lasing is observed under pulsed excitation for as-cleaved dash-in-a-barrier BA lasers for cavity length as short as $140 \mu \mathrm{m}$, demonstrating the high modal gain $\left(\sim 105 \mathrm{~cm}^{-}\right.$

$\left.{ }^{1}\right)$ of the active core.

Fig. 8 shows an example of lasing spectra for both dots in a barrier and DWELL structures in a broad spectral range from 1250 to $1650 \mathrm{~nm}$. In this measurement, the injected current is set to be $75 \mathrm{~mA}$, nearly 3 times the threshold. One can see that for both structures, no excited state emission is observed. The absence of excited state emission in these structures shows that there is a very good gain clamping, contrary to some previous results, reported in particular for the InAs/GaAs system [28].

\subsection{Temperature sensitivity}

In order to optimize the temperature performances of QD-based lasers, we studied the impact of both QDs stacking and p-doping of the active core on $\mathrm{T}_{0}$. We observed that $\mathrm{T}_{0}$ amounts to 60,64 and $70 \mathrm{~K}[29$ for 3 devices of about $600 \mu \mathrm{m}$ cavity length, made of 6, 9 and 12 DWELL layers respectively. This result shows that only increase of the layer number in the laser stack does not allow to significantly increase the $T_{0}$ value. We have hence investigated the influence of active layer p-type doping on $\mathrm{T}_{0} .4$ samples comprising 6 DWELL layers have been grown for that purpose. Different Beryllium-doping levels of the barriers have been studied: undoped reference, structures with estimated holes densities of $0.810^{12} \mathrm{~cm}^{-2}, 1.410^{12} \mathrm{~cm}^{-2}$ and $2.310^{12} \mathrm{~cm}^{-2}$ per DWELL sheet. Fig. 9 shows the variation of the threshold current density in the temperature range from $20^{\circ} \mathrm{C}$ to $80^{\circ} \mathrm{C}$ for these samples. As expected, the introduction of p-doping increases losses $\left(14,25,32\right.$ and $46 \mathrm{~cm}^{-1}$, respectively). However, the value of $\mathrm{T}_{0}$ remains unchanged $(\sim 00 \mathrm{~K})$.

It has been shown previously that the p-doping in InAs/GaAs devices allowed improving significantly the $\mathrm{T}_{0}$ performance [12]. The fact that we did not observe the improvement of $\mathrm{T}_{0}$ through $\mathrm{p}$-doping in our lasers could be attributed either to the shape of the nanostructures or to the band structure. Indeed, a possible explanation might arise from the elongated shape of the dashes that reduces the $3 \mathrm{D}$ confinement and could explain a $\mathrm{T}_{0}$ behaviour similar to that of MQW heterostructures, in which the p-doping effect is of a second order. Further growth study is in progress in order to probe the effect of nanostructures shape on the temperature characteristic. The second explanation is related to the 
band-offset in the valence band which is higher in the InAs/InP system than in the InAs/GaAs one. Indeed, the temperature characteristic of InAs/GaAs QDs, which is mainly determined by the escape of holes, is strongly affected by the p-doping. This p-doping effect could be less significant in the case of InAs/InP QDs, which are more sensitive to Auger effect [30].

It is important to notice that the band-offset in the conduction band in the InAs/InP system is significantly lower than in the InAs/GaAs system. Another solution to increase $\mathrm{T}_{0}$ consists in improving the carrier confinement in the conduction band. For such a purpose, we slightly modified the DWELL design, in such a way that the well thickness is reduced to $6 \mathrm{~nm}$. The narrower QW leads to higher energy level of the excited state of the DWELL structure; as a consequence, the escape rate of electrons from QD to QW is reduced. Fig .10 shows the threshold current density change with the temperature in the range between $20^{\circ} \mathrm{C}$ and $80^{\circ} \mathrm{C}$ for a $900 \mu \mathrm{m}$ Cleaved/High Reflectivity $(\mathrm{C} / \mathrm{HR}) \mathrm{BA}$ laser. One can see that the threshold current density is kept below $3 \mathrm{kA} / \mathrm{cm}^{-2}$ for temperature up to $80^{\circ} \mathrm{C}$. A $\mathrm{T}_{0}$ as high as $100 \mathrm{~K}$ is achieved in that temperature range.

The high $\mathrm{T}_{0}$ of this DWELL structure is confirmed by the results achieved on the single-transverse mode FP lasers. Figure 11 shows the variation of the threshold current with temperature over the $25-85^{\circ} \mathrm{C}$ range for a $\mathrm{BRS}$ laser. The device has a ridge width of $1.5 \mu \mathrm{m}$, a short cavity length of $600 \mu \mathrm{m}$ and two cleaved facets without coatings. We observe that the threshold current at $25^{\circ} \mathrm{C}$ is as low as $12 \mathrm{~mA}$, and that the threshold current vraies slowly with temperature. $\mathrm{T}_{0}$ is measured to be $80 \mathrm{~K}$ in the $25-85^{\circ} \mathrm{C}$ range for an emission wavelength at $1.55 \mu \mathrm{m}$. This result corresponds to a significant improvement of temperature performances with respect to standard $1.55 \mu \mathrm{m}$ aluminum-free MQW-based lasers.

\section{DYNAMIC AND NOISE PROPERTIES OF QD SEMICONDUCTOR LASERS}

\subsection{Dynamic response}

The high internal gain of the developed QDs structures allows the fabrication of very short lasers for high speed direct modulation. For DFB lasers, the grating is defined by E-beam lithography and planarized by a 300nm-thick InP layer regrown by GSMBE. DFB devices investigated in this study have a length of $205 \mu \mathrm{m}$. The rear facet is high reflection (HR) coated and the front facet is as cleaved. The coupling coefficient of the grating is estimated to be in the $20-80 \mathrm{~cm}^{-1}$ range, depending on the laser structure (in particular the stripe width). Figure 12 shows the L-I characteristics of a DFB laser in the $15-85^{\circ} \mathrm{C}$ temperature range, with steps of $10^{\circ} \mathrm{C}$. At $25^{\circ} \mathrm{C}$, the threshold current is as low as $4.8 \mathrm{~mA}$ and the external efficiency reaches $0.3 \mathrm{~mW} / \mathrm{mA}$. The maximum output power exceeds $5 \mathrm{~mW}$ at $85^{\circ} \mathrm{C}$. Figure 13 shows the optical spectrum of the DFB laser at $29 \mathrm{~mA}$. One can see clearly a single-mode operation with a side mode suppression ratio (SMSR) as high as $45.5 \mathrm{~dB}$. The dominant lasing mode at $1512 \mathrm{~nm}$ at $25^{\circ} \mathrm{C}$ is determined by the grating period and the modal effective index. 
Figure 14 shows a typical small-signal modulation response of the $205 \mu \mathrm{m}$ long DFB laser. One can see that the modulation bandwidth is around $6.7 \mathrm{GHz}$, whereas the intrinsic resonance frequency reaches $9.6 \mathrm{GHz}$ at $16 \mathrm{~mA}$. Using an accurate procedure, one can extract from the measured small signal response both the intrinsic laser response and the parasitic response. The latter includes the limitations coming from parasitic series resistance and capacitance, and also from the carriers capture and transport. It should be noted that the carriers capture and transport in QD structures could be an important limiting factor to the modulation bandwidth achievable in these structures. Indeed, same phenomenon as reported in QW structures [31] should also occur in QD lasers.

Figure 15 shows the increase of the intrinsic resonance frequency $f_{R}$, extracted from the small signal response, against the square root of the injection current. The slope efficiency is measured to be as high as $1.9 \mathrm{GHz} / \sqrt{m A}$ at $25^{\circ} \mathrm{C}$. Figure 16 displays the damping rate $\Gamma$ evolution with the squared resonance frequency. Theoretically, the damping rate $\Gamma$ is related to the resonance frequency $f_{R}$ by [27]:

$$
\Gamma=K f_{R}^{2}+\Gamma 0
$$

where $\Gamma_{0}$ is the related to carrier lifetime. From this curve one can determine also the value of the $\mathrm{K}$ factor. The intrinsic maximum bandwidth of the device is given by [27]:

$$
f_{3 d B}=2 \sqrt{2} \pi / K=20.7 \mathrm{GHz}
$$

Such a high value shows clearly the potential of such kind of lasers for high speed modulation, and fully compatible with $10 \mathrm{~Gb} / \mathrm{s}$ bit rate operation.

\subsection{Chirp of directly modulated DFB lasers}

The chirp in a DFB laser is induced through the change of the material refractive index with carrier density. The useful parameter to quantify the chirp is Henry's $\alpha$-parameter. Extensive studies have been devoted to study the $\alpha$-parameter below threshold in InAs/InP QD lasers by using Hakki-Pauli method [32. For telecom application, it is more relevant to measure the $\alpha$-parameter under operating conditions, several times above threshold for example. Figure 17 shows the $\alpha$ parameter of a directly modulated DWELL DFB lasers with 6 QDs layers measured above threshold, with the chirp-tomodulated-power ratio method [33]. In such a method, the laser operates under small-signal direct modulation regime. The phase and amplitude modulation indices are extracted versus the modulating frequency, in the $50 \mathrm{MHz}$ to $20 \mathrm{GHz}$ range. The $\alpha$-parameter is then measured from the chirp to modulated power ratio in the high modulation frequency range. One can observe that the $\alpha$-parameter increases slightly from 4 to 6 with the injection current above threshold. With respect to previous DWELL laser generation, the $\alpha$-parameter is significantly stabilized above threshold, whereas 
the differential gain is higher. Such a result means that the injected carriers contribute more efficiently to laser gain and do not increase the population in wetting layer or excited states. This can be due as well to improved carrier transport and capture in the new generation QD structure, leading to much better gain clamping above threshold owing to a reduced nonlinear gain. Further improvement is expected with further reduced threshold current density.

\subsection{Noise properties}

Relative Intensity Noise (RIN) of laser diodes, due to an increase of noise figure, is a limiting factor for the use of laser diodes in high speed transmission systems. RIN originates mainly from the coupling of spontaneous emission to the lasing mode and reduces when the damping rate is decreased [27,34]. As the damping rate is inversely proportional to differential gain, higher differential gains should lead to a reduction of RIN. Furthermore, QD material, thanks to their low dimensionality, should allow for a reduction in population inversion factor and hence, to obtain lower spontaneous emission rates compared to QW material. At the same time, reduction of the density of states allows for higher differential gains that also favors the reduction of the RIN level. Figure 18 shows the RIN measured on (a) a $1 \mathrm{~mm}$ long dash-in-a-barrier FP laser, and (b) a DWELL FP laser, both emitting at $1.55 \mu \mathrm{m}$. One can see that both lasers have quite high RIN level in the low frequency range $(<2 \mathrm{GHz})$, which comes from the mode partition noise, due to the multimode operation of the FP cavity. For low injection current (100 mA), resonance due to relaxation oscillations can be clearly observed, with a resonance frequency around $5.5 \mathrm{GHz}$ for (a) and $7.5 \mathrm{GHz}$ for (b). For higher injection current, the relaxations oscillations are strongly damped due to higher nonlinear gain introduced by intraband phenomena (spectral hole burning or carrier heating) or carrier transport in QD structures. For these injection current values, the laser exhibits low and flat relative intensity noise figure of below $-157 \mathrm{~dB} / \mathrm{Hz}$ in the $10-20 \mathrm{GHz}$ range. It can be noticed that the RIN in the DWELL laser is slightly lower than that in the dash-in-a-barrier. These noise levels are comparable with what can be measured on quantum well structures. Further studies are currently performed in order to explain this limited RIN reduction and to design structures for lower RIN.

\subsection{Direct modulation at $10 \mathrm{~Gb} / \mathrm{s}$}

The $10 \mathrm{~Gb} / \mathrm{s}$ NRZ laser modulation is realized with a Pseudo Random Binary Sequence (PRBS) generator emitting $2^{31}-1$ long words. The electrical signal modulation depth is controlled thanks to an amplifier and an attenuator and is fed into the laser through a bias tee. The emitted optical NRZ signal is sent to a $10 \mathrm{~Gb} / \mathrm{s} \mathrm{SDH}$ receiver, followed by a bit-error-rate (BER) measurement setup.

Figure 19 shows the BER measured at 10Gb/s when modulating directly a DWELL FP laser, in the $25-75^{\circ} \mathrm{C}$ range [35]. The laser used has a $310 \mu \mathrm{m}$ length, with HR coating on the rear facet. The threshold current is $3.9 \mathrm{~mA}$ and the external efficiency reaches $0.28 \mathrm{~mW} / \mathrm{mA}$ at $25^{\circ} \mathrm{C}$. The characteristic temperature $\mathrm{T}_{0}$ of the $\mathrm{HR} /$ cleaved laser equals $47 \mathrm{~K}$ in the $25-75^{\circ} \mathrm{C}$ range, whereas the efficiency drops by only $1.3 \mathrm{~dB}$. The temperature stability is typical of InGaAsP based structures. The bias current is $44 \mathrm{~mA}$ at $25^{\circ} \mathrm{C}$ and $64 \mathrm{~mA}$ at $75^{\circ} \mathrm{C}$. Floor-free back-to-back $10 \mathrm{~Gb} / \mathrm{s} \mathrm{BER}$ has been 
obtained with a sensitivity at $\mathrm{BER}=10^{-10}$ of $-13.5 \mathrm{dBm}$ and $-9.6 \mathrm{dBm}$ at $25^{\circ} \mathrm{C}$ and $75^{\circ} \mathrm{C}$ respectively. Further improvements are expected using the new DWELL design that demonstrates higher temperature characteristics (see section II).

Thanks to performing intrinsic dynamic properties and low chirp, the $205 \mu \mathrm{m}$ long BRS DFB QDs laser has allowed to demonstrate transmission of the directly modulated signal at $10 \mathrm{~Gb} / \mathrm{s}$. In that case, the average applied current is $29.4 \mathrm{~mA}$ and the extinction ratio obtained at the laser output is close to $6 \mathrm{~dB}$. The relatively low extinction ratio is attributed to electrical injection dynamic limitations of the DFB laser. Fig.20 shows the bit error rate measurement of the directly modulated DFB QDs laser at $25^{\circ} \mathrm{C}$ and at $10 \mathrm{~Gb} / \mathrm{s}$, before and after transmission through 2,8 and $10 \mathrm{~km}$ of standard fibres. The global dynamic response of the device allows floor free bit error measurement at $10 \mathrm{~Gb} / \mathrm{s}$ with a 10 ${ }^{10}$ sensitivity of $-13 \mathrm{dBm}$, typical of the used SDH receiver. Moreover, and despite the linewidth enhancement factor larger than 4.5 at the operating point, floor free metropolitan distance transmission is achieved with a penalty of $0.8,4$ and $5 \mathrm{~dB}$ for transmission through 2,8 and $16 \mathrm{~km}$ of fibers respectively. This transmission reveals the good quality of the modulated output signal at $10 \mathrm{~Gb} / \mathrm{s}$.

\section{QD-BASED SEMICONDUCTOR OPTICAL AMPLIFIER}

In order to investigate their static and dynamic gain properties, QD SOA are realized with the same type of QDs Fabry-Perot structures, with anti-reflection coating on both facets. The active waveguide is tilted $7^{\circ}$ in order to further reduce facet reflectivity. Figure 21 shows the typical gain spectrum of a QD SOA of the $1.5 \mathrm{~mm}$ length. One can observe a $3 \mathrm{~dB}$ gain bandwidth of $50 \mathrm{~nm}$, and a total amplification bandwidth (gain > $0 \mathrm{~dB}$ ) of $210 \mathrm{~nm}$. Such results are very similar to those published in $[36,37,38]$. Such an optical bandwidth is slightly higher to the one obtained with standard quantum well SOA, but lower than the gain bandwidth of low confinement bulk SOA, typically $70 \mathrm{~nm}$.

Figure 22 displays the typical gain and noise figure (NF) of a QD-SOA chip against the injection current, measured at $1500 \mathrm{~nm}$. The measurement is done for TE polarization. Due to the polarization sensitivity of QD-SOA, special care was taken when measuring their NF [39].The intrinsic chip gain reaches $20 \mathrm{~dB}$ for an injection current of $200 \mathrm{~mA}$, while the NF is decreased to $6 \mathrm{~dB}$. Such a value is to be compared with $5 \mathrm{~dB}$ reported in [38], the lowest NF value published so far for QD-SOA. From the point of view of NF, there is still room of improvement for our QD-SOAs, as NF for packaged bulk or QW SOAs can be as low as $6 \mathrm{~dB}$ (see for instance [40]). It is to be noted that the NF of a packaged SOA has an additional contribution from the the coupling losses between the input fiber and the SOA chip.

QDs based SOA is also an efficient medium for non-linear phenomenon such as four-wave mixing (FWM). Fig. 23 shows the output spectrum of such a SOA, by injecting simultaneously a pump and a probe with a $100 \mathrm{GHz}$ frequency spacing. One can clearly observe the two newly generated wavelength components. The inset of this figure shows the FWM efficiency, defined as the output conjugate signal power normalised by the output probe power and the squared output pump power, against the gain confinement factor. It shows that the QD based SOAs have the same FWM 
efficiency as their bulk counterpart, although the optical confinement factor is nearly five times lower for the QD device. The Section VI will show how such non-linearities can be favorably exploited in mode-locked lasers.

\section{QD BASED MODE-LOCKED LASER}

\subsection{Phase correlation in passively mode-locked QD lasers}

The typical optical spectrum of a $1080 \mu \mathrm{m}$ long QDs FP laser is represented in Figure 24. The full spectrum width is around $10 \mathrm{~nm}$, suggesting the capability to obtain sub-picosecond pulses. Without any saturable absorption section, passive mode-locking is observed at DC bias condition. The resulting photocurrent is observed through an electrical spectrum analyser (ESA) with a span of $1 \mathrm{MHz}$ and a resolution bandwidth of $3 \mathrm{kHz}$. Figure 25 (a) shows an example of a radio-frequency $(\mathrm{RF})$ spectrum of the photocurrent for a fixed operating point. We observe on this figure that the photocurrent exhibits a lorentzian shape at a frequency of $39 \mathrm{GHz}$. The measured spectral linewidth at half maximum of this RF signal is about $15 \mathrm{kHz}$.

As in the case of MQW DBR lasers, the mode correlation between different modes is confirmed by measuring RF beating spectrum of three couples of modes [21], as marked in Fig. 21. Figure 25 (b), (c) and (d) displays the RF spectra of the photocurrent representing the beating component of these couples of modes. We observe that all these spectra exhibit a lorentzian shape. The measured spectral linewidths at half maximum are all about $15 \mathrm{kHz}$, which is the same as the spectral linewidth of the entire mode-beating signal. Therefore, this experiment shows that the detected beating signal is composed of beating notes from all adjacent modes, with equal linewidths. Since phase noise is the origin of spectral linewidth, such a result proves that the relative phases of adjacent modes have the same phase noise characteristics, and the modes are partly correlated under passive mode-locking operation, through the efficient FWM in the QD active layer.

The linewidth of each longitudinal mode is also measured by setting the bandpass of the monochromator to 0.1 $\mathrm{nm}$ in order to measure their spectral linewidths, using a self-homodyne technique based on an interferometer, and to compare them to the linewidth of the generated beating signal. We found that the linewidth of each longitudinal mode is of the order of $10 \mathrm{MHz}$, resulting from the phase fluctuations upon spontaneous emission. However, the mode-beating linewidth is largely narrower than that of the longitudinal modes as in FP semiconductor lasers, demonstrating that the phases fluctuations of these longitudinal modes are largely synchronized.

Figure 26 displays the beat note linewidth as a function of the gain confinement factor, summarizing the results for bulk, MQW and QDs laser structures. The inset shows a comparison of the RF spectrum between a bulk and a QDs laser. One can observe that the beat note linewidth is of the order of $\mathrm{MHz}$ for lasers with bulk active layer, several hundreds of $\mathrm{kHz}$ for MQW lasers and tens of $\mathrm{kHz}$ for QDs lasers. The extremely narrow linewidth for QDs lasers is 
believed to be a consequence of reduced spontaneous emission rate coupled to the lasing mode, and sufficient four-wavemixing in these QDs structures, as demonstrated in section V.

\subsection{Application of QD lasers for all-optical clock recovery application}

We demonstrated recently that, thanks to the narrow spectral linewidth of the free-runing self-pulsating signal, QDs based lasers allows for the suppression of high frequency jitter, with a cut-off frequency corresponding exactly to that required by the ITU-T recommendation G825.1 for clock recovery at $40 \mathrm{GHz}[24,25,26]$. We summarize the main results and explain why the mode-beating linewidth is the key parameter for this application.

It has been found both theoretically and experimentally that the phase noise power spectral density (PSD) of the SP laser recovered clock is given by [26]:

$$
S_{\phi_{L}}(f)=H_{s}(f),\left(S_{\phi_{i n}}(f)+\frac{\Delta v}{2 \pi f_{L}^{2}}\right)
$$

where $S_{\phi_{L}}\left(S_{\phi_{\text {in }}}\right)$ stands for the phase noise PSD of the recovered clock (input signal), $f$ the analysis frequency, $\Delta v$ the SP laser free running spectral linewidth, $\mathrm{f}_{\mathrm{L}}$ the locking characteristic frequency of the injection locking phenomenon. The fist term in brackets of Eq. (5) represent the the phase noise $S_{\phi_{\text {in }}}$ of the input signal, and the second one accounts for the phase noise introduced by the SP laser itself. $\mathrm{H}_{\mathrm{s}}(\mathrm{f})$ is the phase noise transfer function of the locked SP laser expressed by:

$$
H_{s}(f)=\frac{1}{1+\left(\frac{f}{f_{L}}\right)^{2}}
$$

This transfer function represents a second order low pass filter with a $20 \mathrm{~dB} /$ decade decrease and with a $-3 \mathrm{~dB}$ cutoff frequency corresponding to $f_{L}$. The key parameter here is the cut-off frequency $f_{L}$, which has been shown to be proportionnal to the mode-beating linewidth. It is thus essential, in order to improve all-optical clock recovery performances, to reduce the mode-beating linewidth.

QDs based lasers are ideally suited for the clock recovery application owing to the narrow mode-beating linewidth. The jitter removal can be clearly demonstrated by injecting a jittered signal into the QD-FP laser. Figures 27 gives the eye diagram of the incoming jittered $2^{31}-1$ optical time division multiplexing (OTDM) signal, and the corresponding recovered clock from the QD-FP laser, showing a drastic decrease of the time jitter. Again, to get more insight to this phenomenon, figure 24 shows the measured phase noise spectra of the recovered clocks obtained with different PRBS lengths of the jittered incoming OTDM signal, as well as the phase noise spectrum of the corresponding jittered input signal. The comparison between the PN spectra of the recovered clock with that of the jittered input signal clearly explains the drastic decrease of time jitter observed on the sampling scope through the filtering effect operated by the QD-FP laser. Hence, the calculation of the rms jitter from the PN measurements shows a reduction from 1.37 ps for 
the input to $0.31 \mathrm{ps}$ for the recovered clock in both cases (PRBS of $2^{7}-1$ and $2^{31}-1$ ). These results undoubtedly demonstrate the efficiency of high frequency jitter suppression operated by the QD-FP laser, whatever the OTDM PRBS length.

\section{CONCLUSION}

Recent advance on GSMBE growth of self-organized InAs/InGaAsP QD emitting at 1.55 $\mu$ m has been reported. We have investigated both dashes-in-a-barrier and dashes-in-a-well buried ridge stripe FP and DFB lasers. CW roomtemperature lasing operation on ground state of cavity length as short as $200 \mu \mathrm{m}$ has been achieved, demonstrating the high modal gain of the active core. A threshold current density as low as $110 \mathrm{~A} / \mathrm{cm}^{2}$ per QD layer has been obtained for infinite-length DWELL laser. Thanks to an optimized DWELL design, a $\mathrm{T}_{0}$ of $80 \mathrm{~K}$ for single transverse mode lasers in the temperature range between $25^{\circ} \mathrm{C}$ and $85^{\circ} \mathrm{C}$ has been demonstrated, keeping a threshold current density as low as $3 \mathrm{kA} / \mathrm{cm}^{2}$ over the full temperature range. Low RIN level has been measured for both dashes in a barrier and DWELL FP laser structures. BRS type single mode DFB lasers are also demonstrated for the first time, exhibiting a side-mode suppression-ratio as high as $45 \mathrm{~dB}$. Such DFB lasers allow the first floor free $10 \mathrm{~Gb} / \mathrm{s}$ direct modulation for back-to-back and transmission over $16 \mathrm{~km}$ standard optical fiber. Gain, noise and FWM of QD-based semiconductor optical amplifiers have been reported. In particular, we have shown that the QDs based SOA has the same FWM efficiency as the bulk counterpart, although the optical confinement factor is nearly five times lower for the QD device. Furthermore, we demonstrate that QD FP lasers, owing to the small confinement factor and the 3D quantification of electronic energy levels, exhibit a beating linewidth as narrow as $15 \mathrm{kHz}$.. Such an extremely narrow linewidth, compared to their QW or bulk counterparts, leads to the excellent phase noise and time jitter characteristics when QD lasers are actively modelocked.

These state-of-the-art results demonstrate the high-quality of quantum dashes fabrication approaching the industrial applications and opening the way to further improvements of devices performances for optical telecommunication. There are several directions on which works have to be done. The first will be to further refine the control on nanostructure shape in order to reinforce the 3D quantum confinement. The second will be to further optimize the design of QD-based heterostructures in order to overcome the limitations coming from carrier transport that limit the dynamic properties of such QD-based lasers. Special attention will also be paid to reduce noise in QD lasers. Finally, QD based mode-locked lasers will be further investigated for several applications in optical fiber communications and millimetre wave generation to explore their excellent phase noise and time jitter characteristics.

\section{ACKNOWLEDGEMENT}

The authors wish to acknowledge the support of the EU through the ZODIAC project and the French RNRT ROTOR project. They acknowledge also the fruitful discussions with A. Ramdane and B. Lavigne and the TEM observations provided by G. Patriarche. 
- 14 - 
$-15-$ 


\section{Figure Captions}

Fig.1: Plan-view TEM image of a stack of 6 QDs layers.

Fig. 2: Schematic representation of QDs based active structures: dashes inserted directly in the barrier, or within an intermediate quantum well.

Fig.3: Cross-sectional TEM image of a stack of 3 nominally identical QDs layers.

Fig.4: Photoluminescence linewidth of stacked QDs as a function of the number of stacked layers.

Fig.5: Photoluminescence spectra of a laser active core comprising 6 QD layers.

Fig.6: Threshold current density of $50 \mu \mathrm{m}$-wide BA lasers versus reciprocal cavity length for dash-in-a-barrier ( $\square$ ) and dash-in-a-well structures $(\diamond)$.

Fig. 7 Reciprocal external efficiency as a function of the cavity length for a DWELL BA laser.

Fig. 8 Output emission spectra of both dots in a barrier and DWELL lasers in the large spectral range from 1250 to 1650 nm.

Fig. 9 Threshold current density variation with temperature of DWELL BA lasers with Beryllium-doping density of 0.8 $10^{12} \mathrm{~cm}^{-2}, 1.410^{12} \mathrm{~cm}^{-2}$ and $2.310^{12} \mathrm{~cm}^{-2}$ per DWELL sheet, respectively

Fig. 10 Threshold current density variation with temperature of an optimized DWELL BA lasers with reduced well thickness.

Fig. 11 Threshold current variation with temperature of an optimized single-transverse mode DWELL laser.

Fig. 12. Light output characteristics of a $205 \mu \mathrm{m}$-long BRS DFB QDs laser, with HR coating on the rear facet and cleaved front facet, in the $15-85^{\circ} \mathrm{C}$ temperature range.

Fig. 13. Spectrum of the 205 $\mu$ m-long BRS DFB QDs laser 
Fig. 14. Small-signal modulation response of a $310 \mu \mathrm{m}$ long BRS QDs laser, with HR coating on the rear facet and cleaved front facet, at $60 \mathrm{~mA}$ and $25^{\circ} \mathrm{C}$. "Measured" corresponds to the global response of the device, "Extracted intrinsic" is the extracted intrinsic response, and "Extracted parasitic" is the extracted parasitic response including laser's resistivity and capacity, and carriers transport and capture.

Fig. 15. Resonance frequency versus current of the $205 \mu \mathrm{m}$-long BRS DFB QD laser at $25^{\circ} \mathrm{C}$.

Fig. 16. Damping factor as a function of the squared resonance frequency of the $205 \mu \mathrm{m}$-long BRS DFB QD laser at $25^{\circ} \mathrm{C}$.

Fig. 17. Henry's $\alpha$-parameter of a directly modulated DWELL DFB laser above the threshold.

Fig. 18. Relative intensity noise of $1 \mathrm{~mm}$-long (a) dash-in-a-barrier, and (b) DWELL Fabry-Perot lasers.

Fig. 19. Back-to-back bit error rate evaluation of a HR/cleaved QDs Fabry-Perot laser at $25^{\circ} \mathrm{C}$ and $75^{\circ} \mathrm{C}$, and corresponding filtered eye-diagrams.

Fig. 20. Back-to-back and 2 to $16 \mathrm{~km}$ transmission bit error rate evaluation of the $205 \mu \mathrm{m}$ HR/cleaved QDs DFB laser at $25^{\circ} \mathrm{C}$.

Fig. 21. Measured gain spectrum of a QDs SOA.

Fig. 22 Typical gain and noise figure variations of a QD-SOA chip as a function of the injection current.

Fig. 23 Output optical spectrum of a QD SOA. The inset shows the FWM efficiency.

Fig. 24 Optical spectrum of a passively mode-locked Fabry-Perot laser

Fig. 25: Mode-beating spectrum of passively locked FP QD laser: (a) whole spectrum, (b), (c) and (d) displaying the beating component of the different couples of modes marked in figure 24.

Fig. 26: Evolution of the beating linewidth with the gain confinement factor. The inset shows a comparison of the RF spectrum between a bulk and a QDs laser.

Fig. 27. Top: Eye diagram of the incoming jittered $2^{31}-1$ OTDM signal (left) and the recovered clock (right). Bottom: Phase noise measurements performed on the QD-FP laser clock and on input signal. 


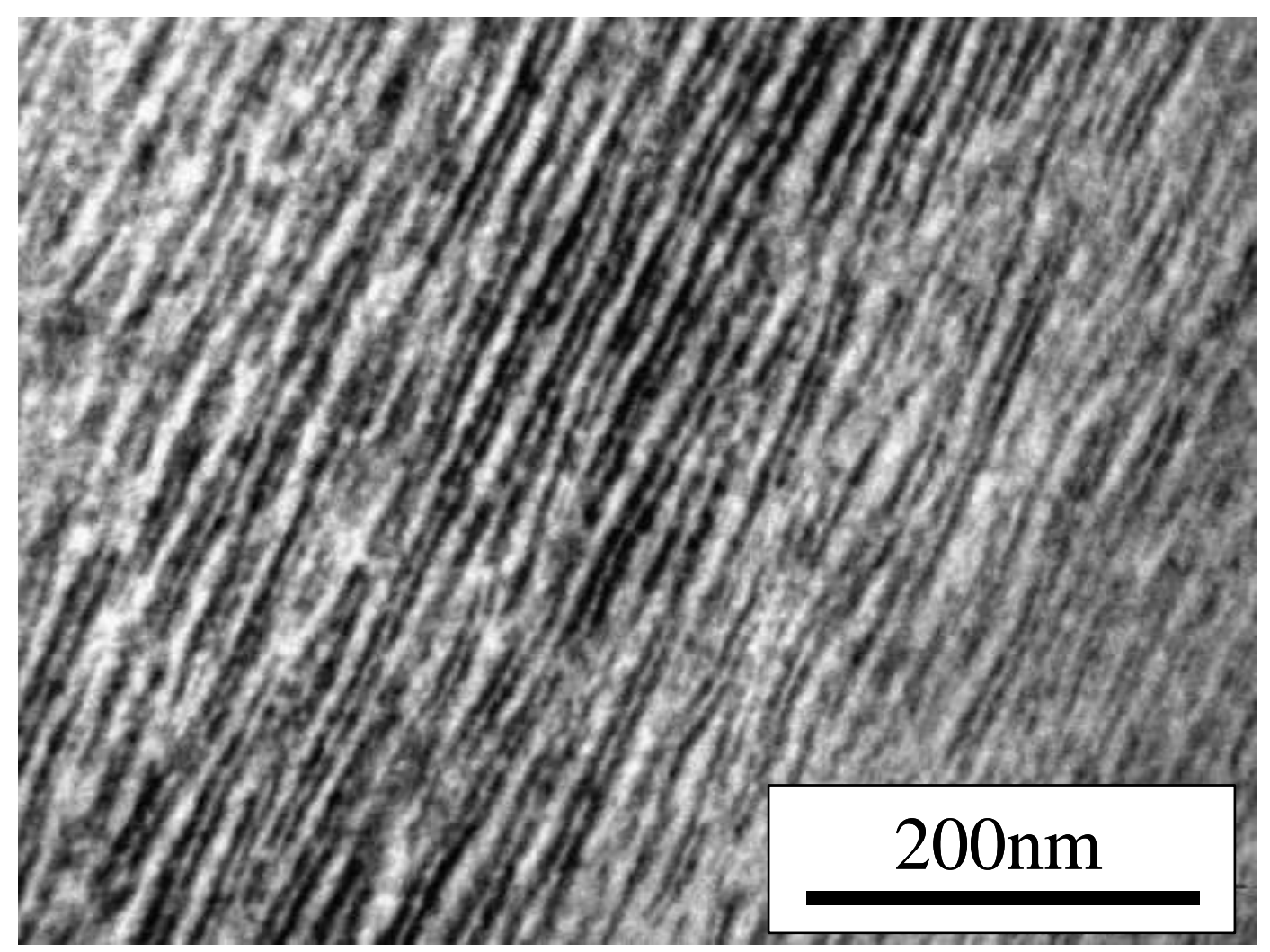

Fig. 1

$-18-$ 


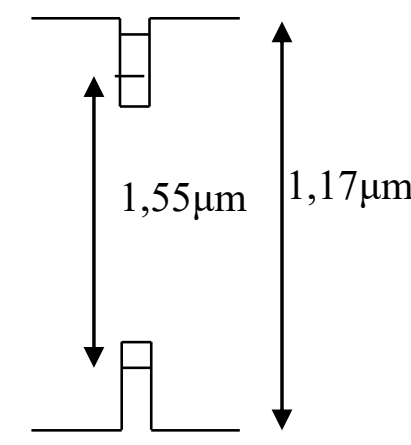

Dot-in-a-barrier

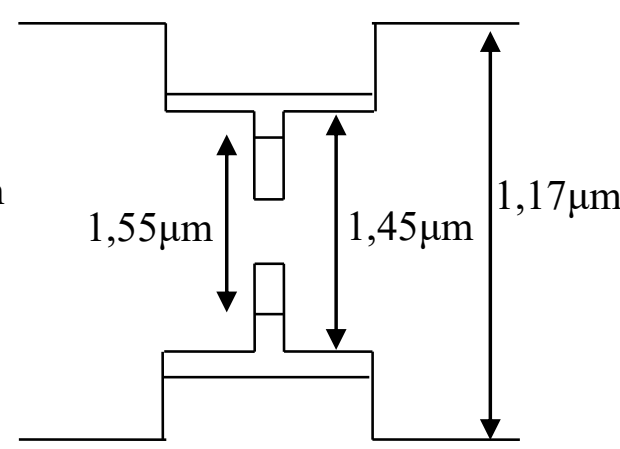

Dot-in-a-well

Fig. 2 


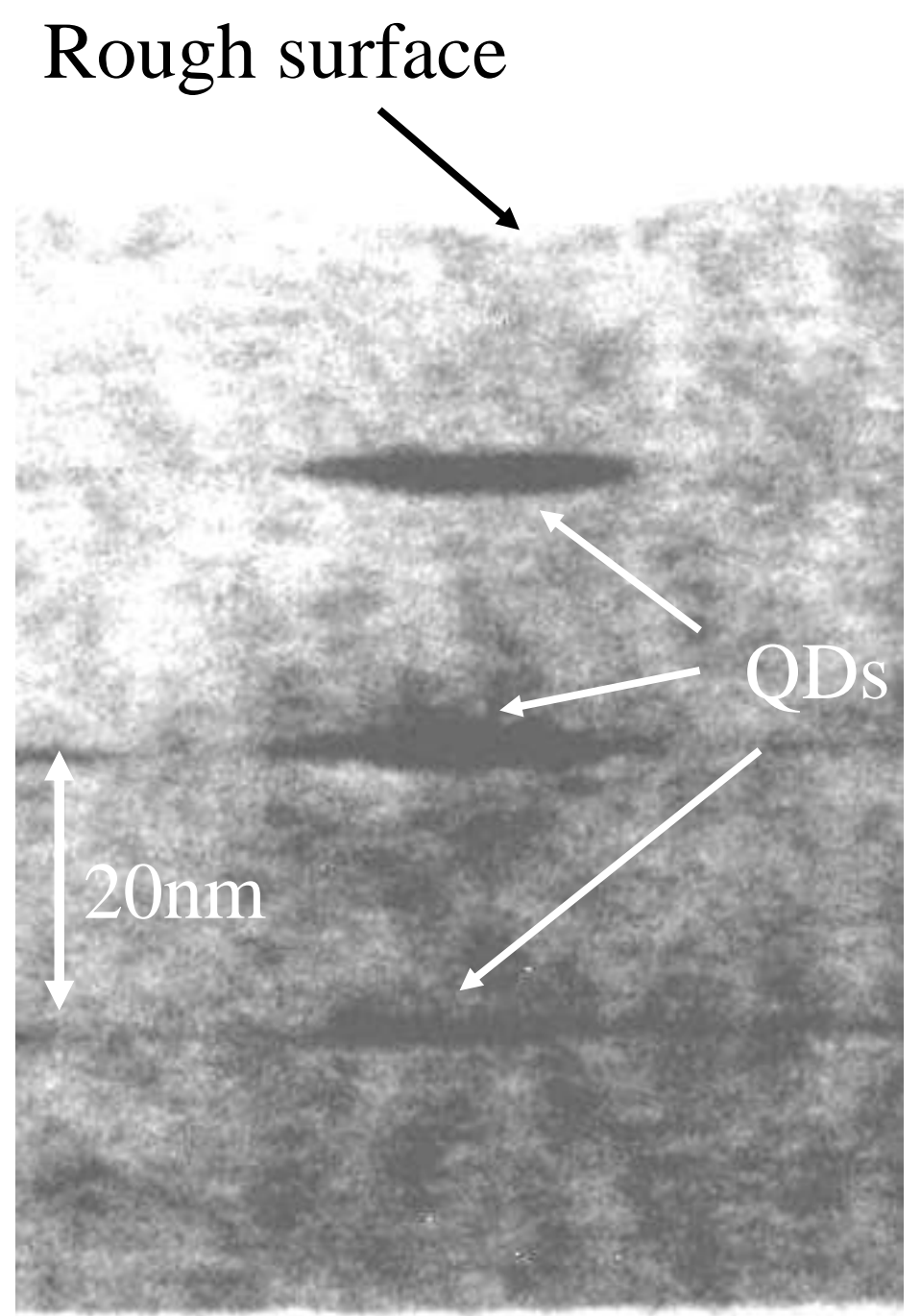

Fig. 3 


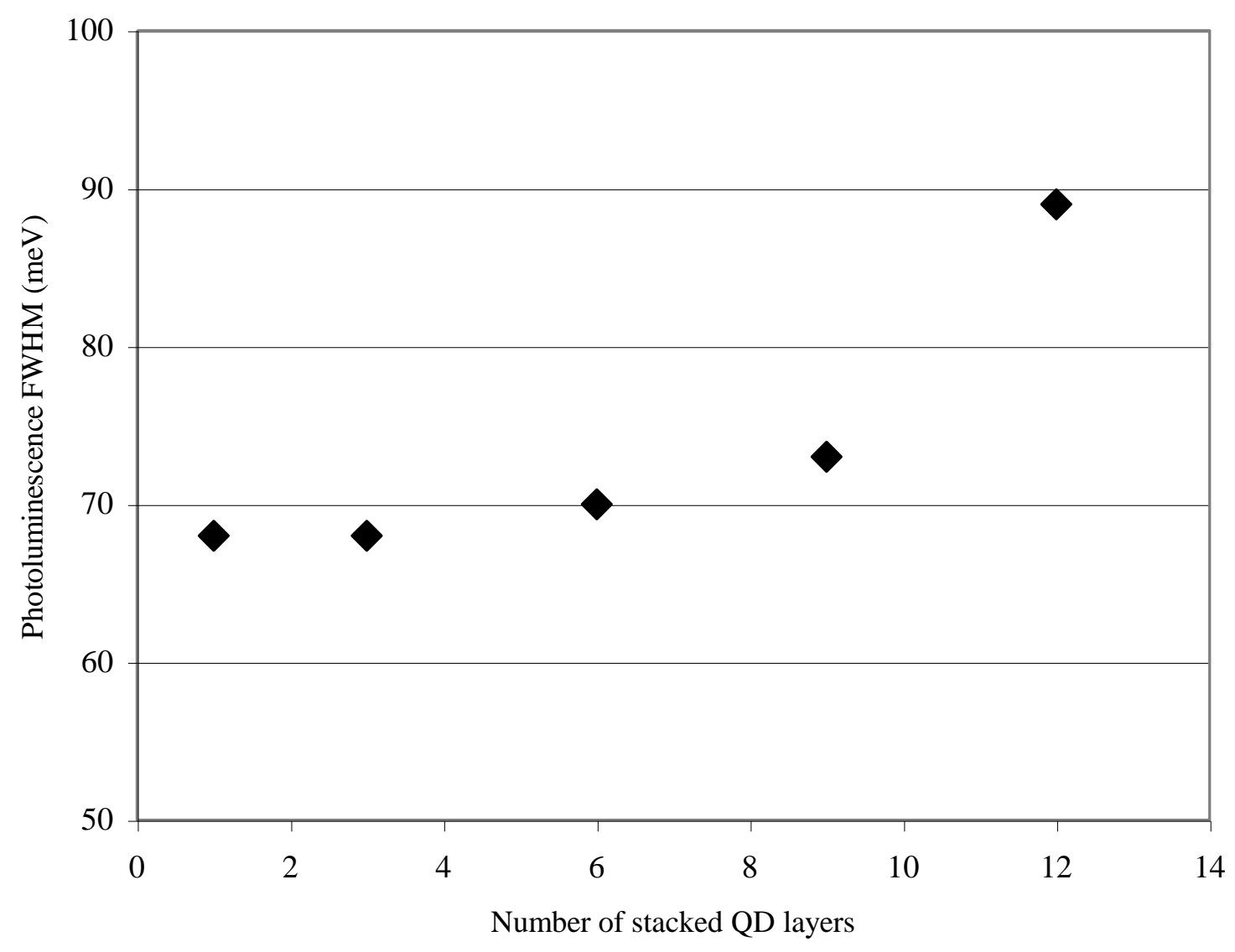

Fig. 4 


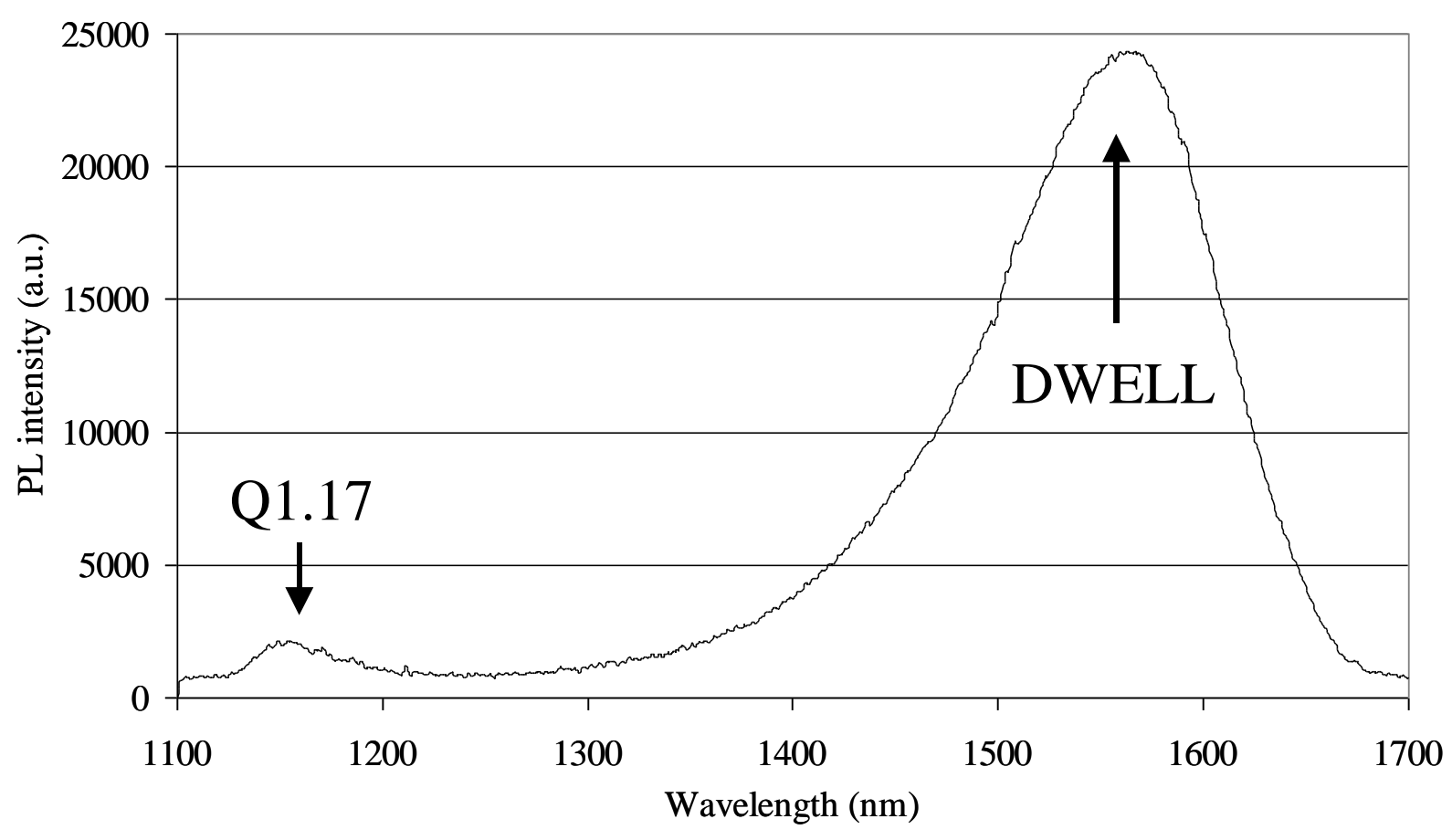

Fig. 5 


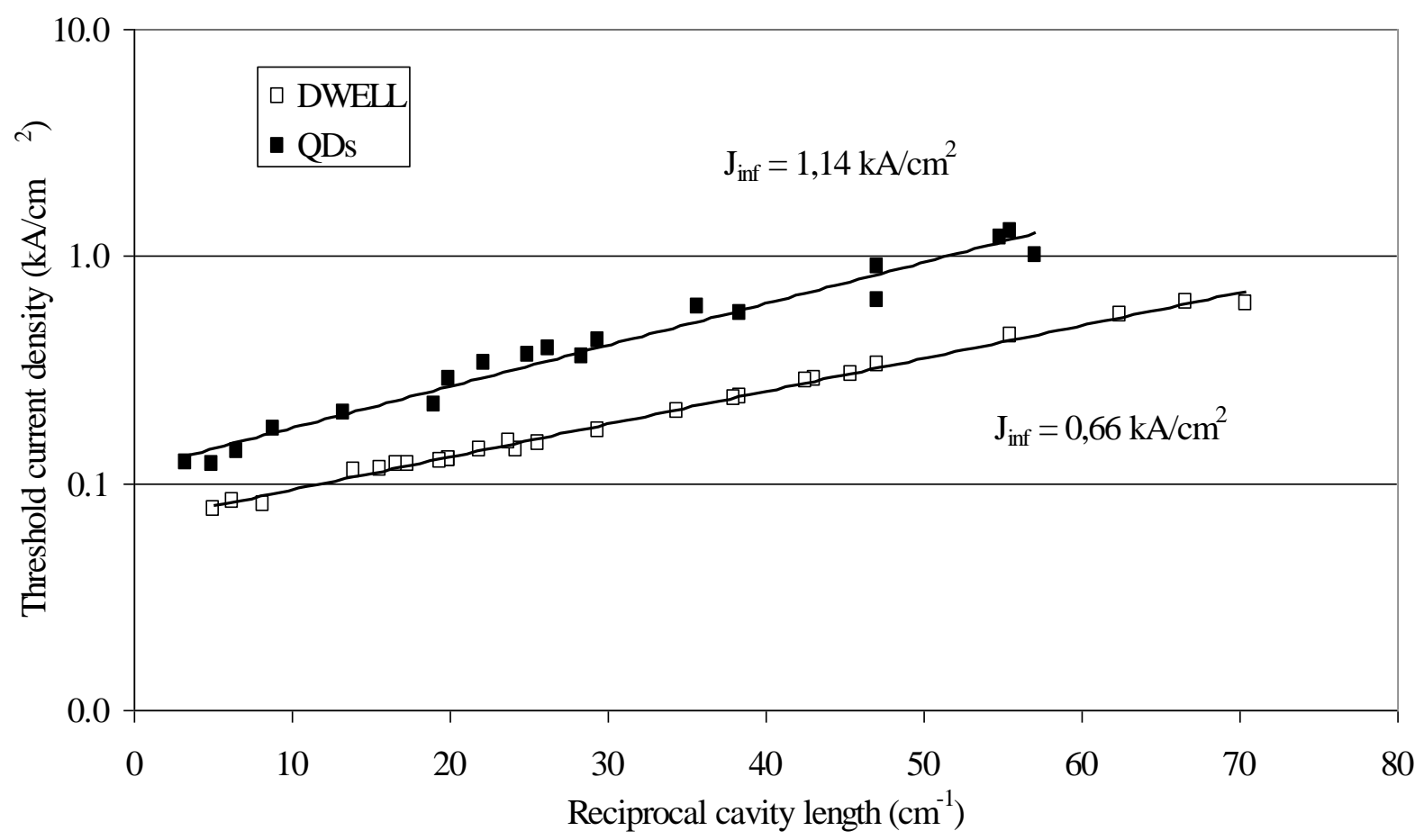

Fig. 6 


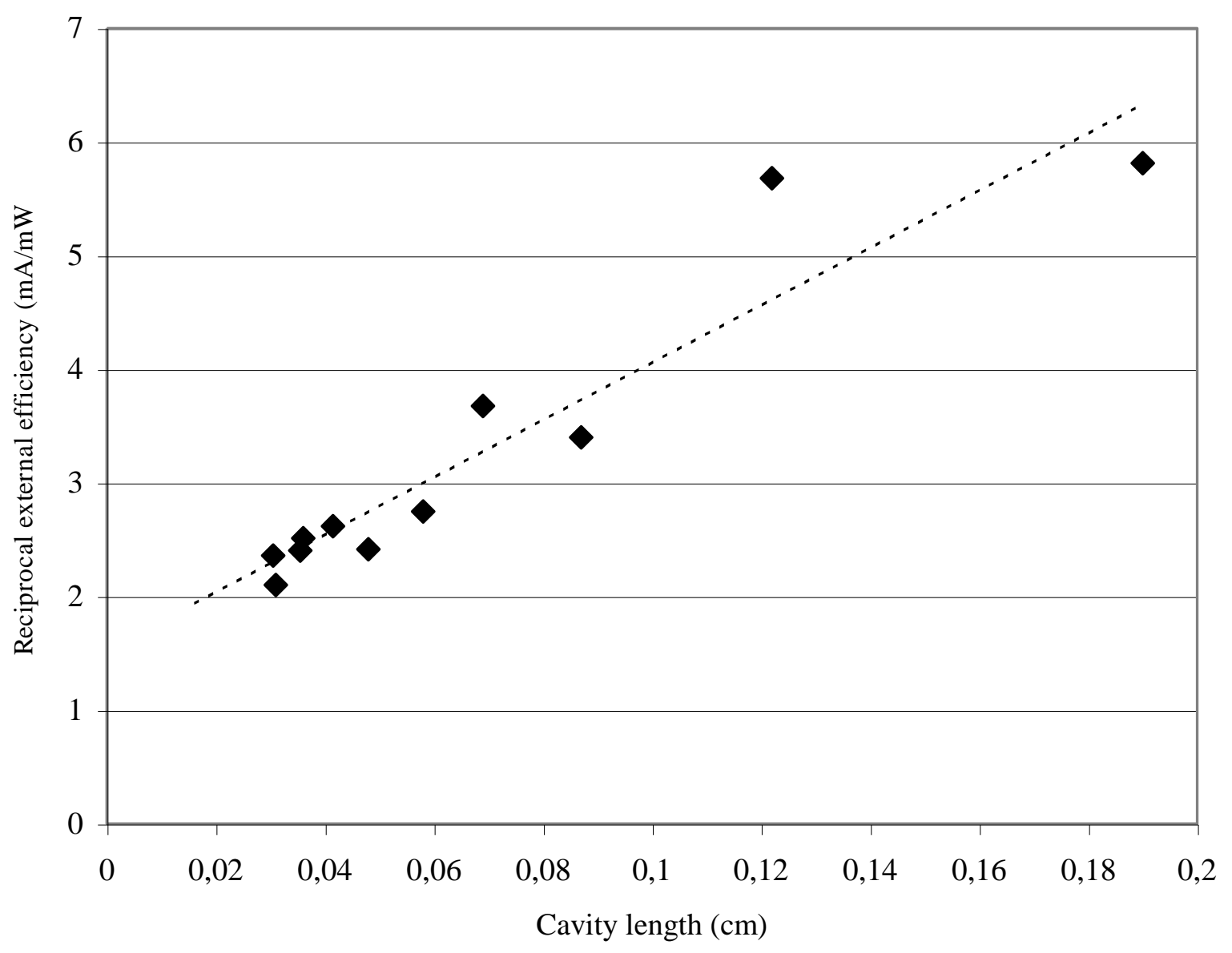

Fig.7 


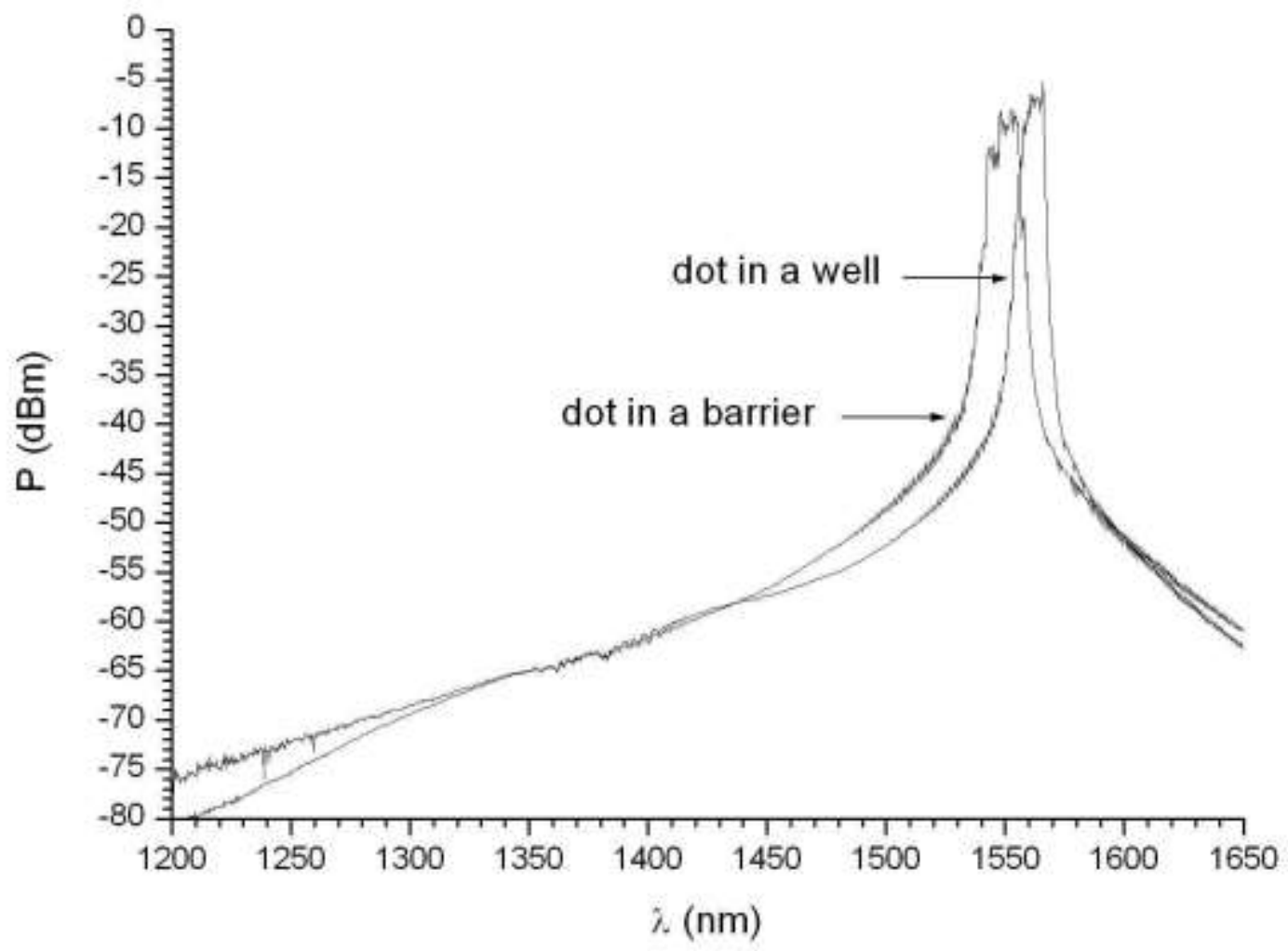

Fig. 8 


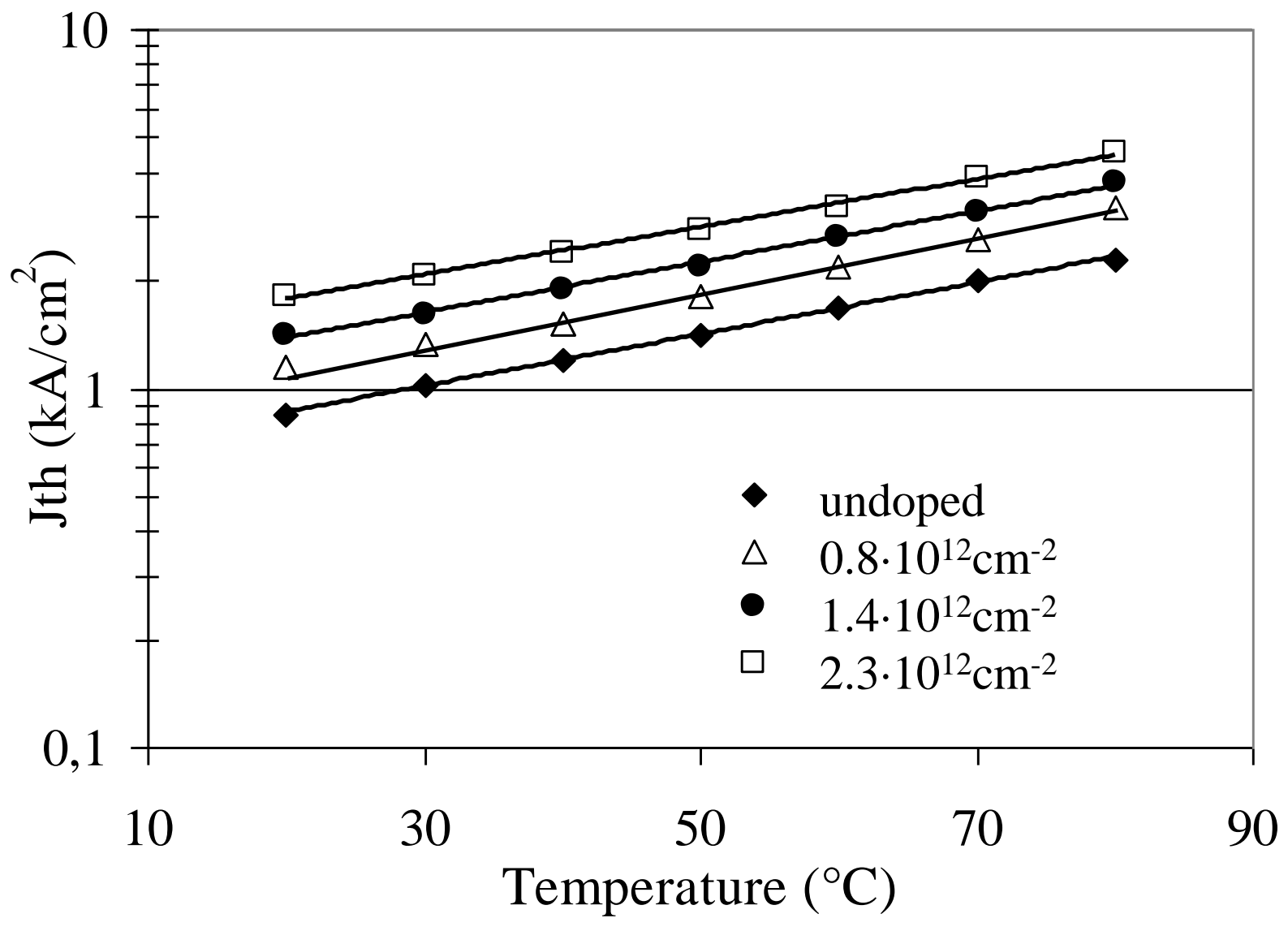

Fig. 9 


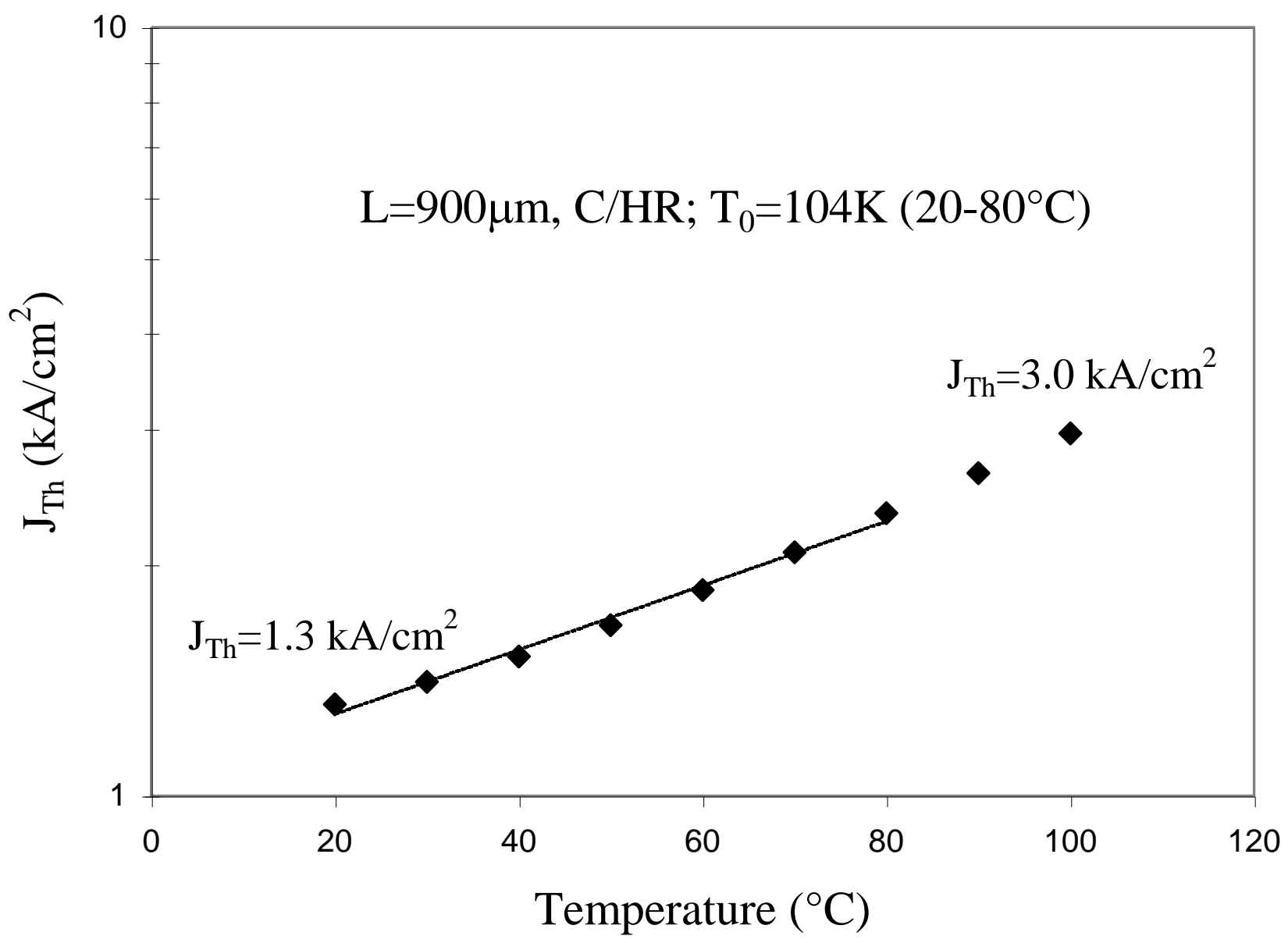

Fig. 10 


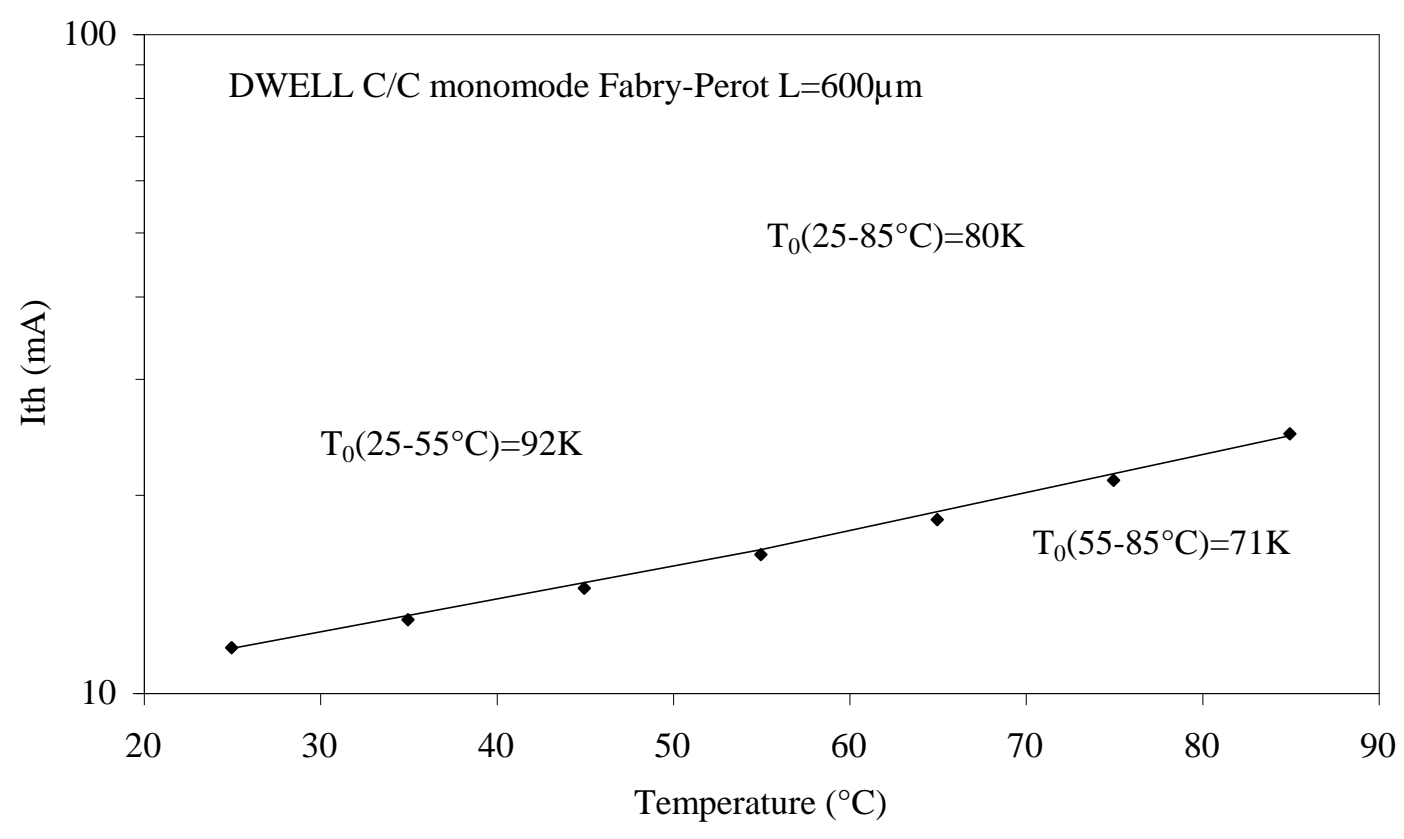

Fig. 11 


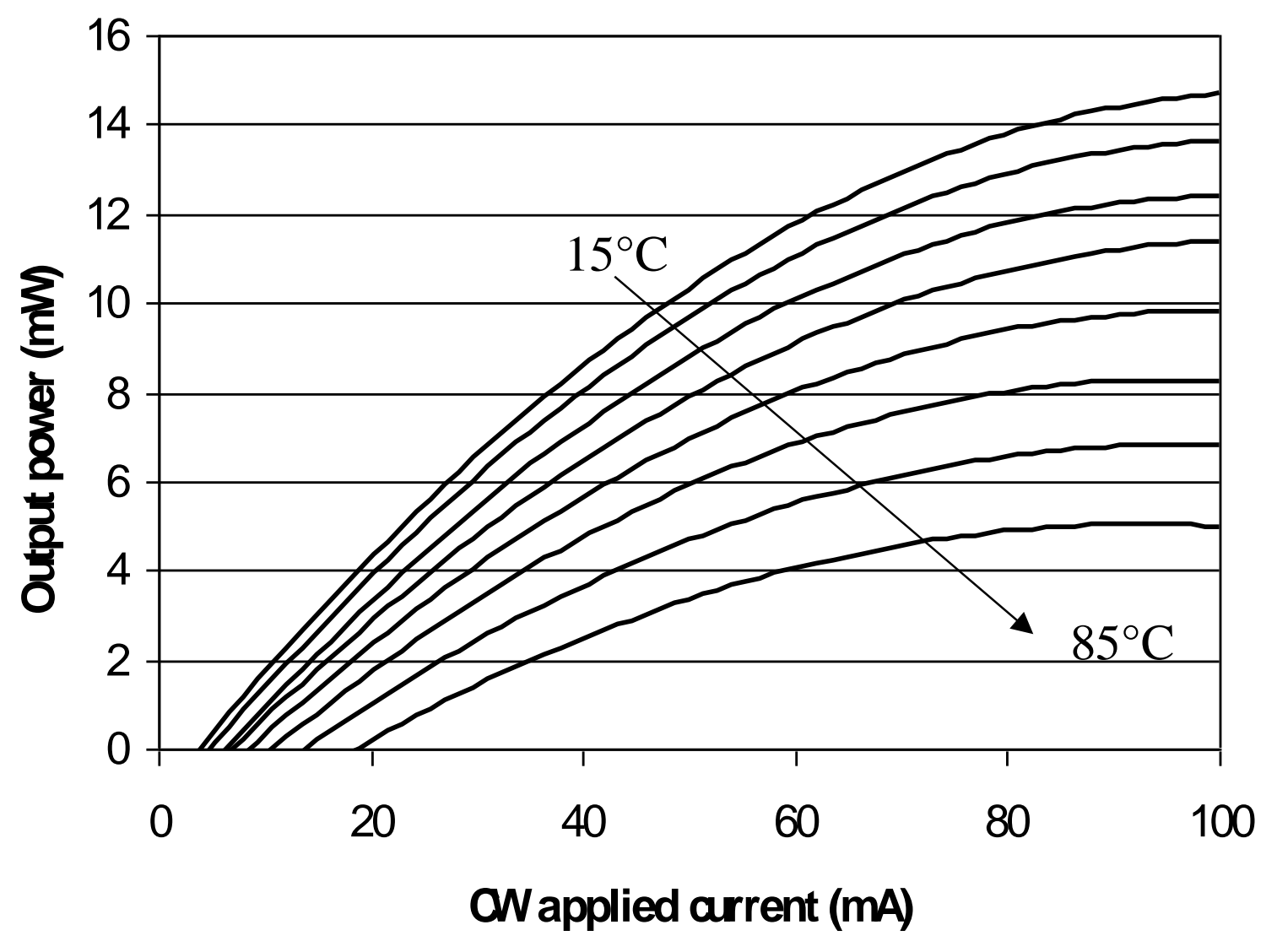

Fig. 12 


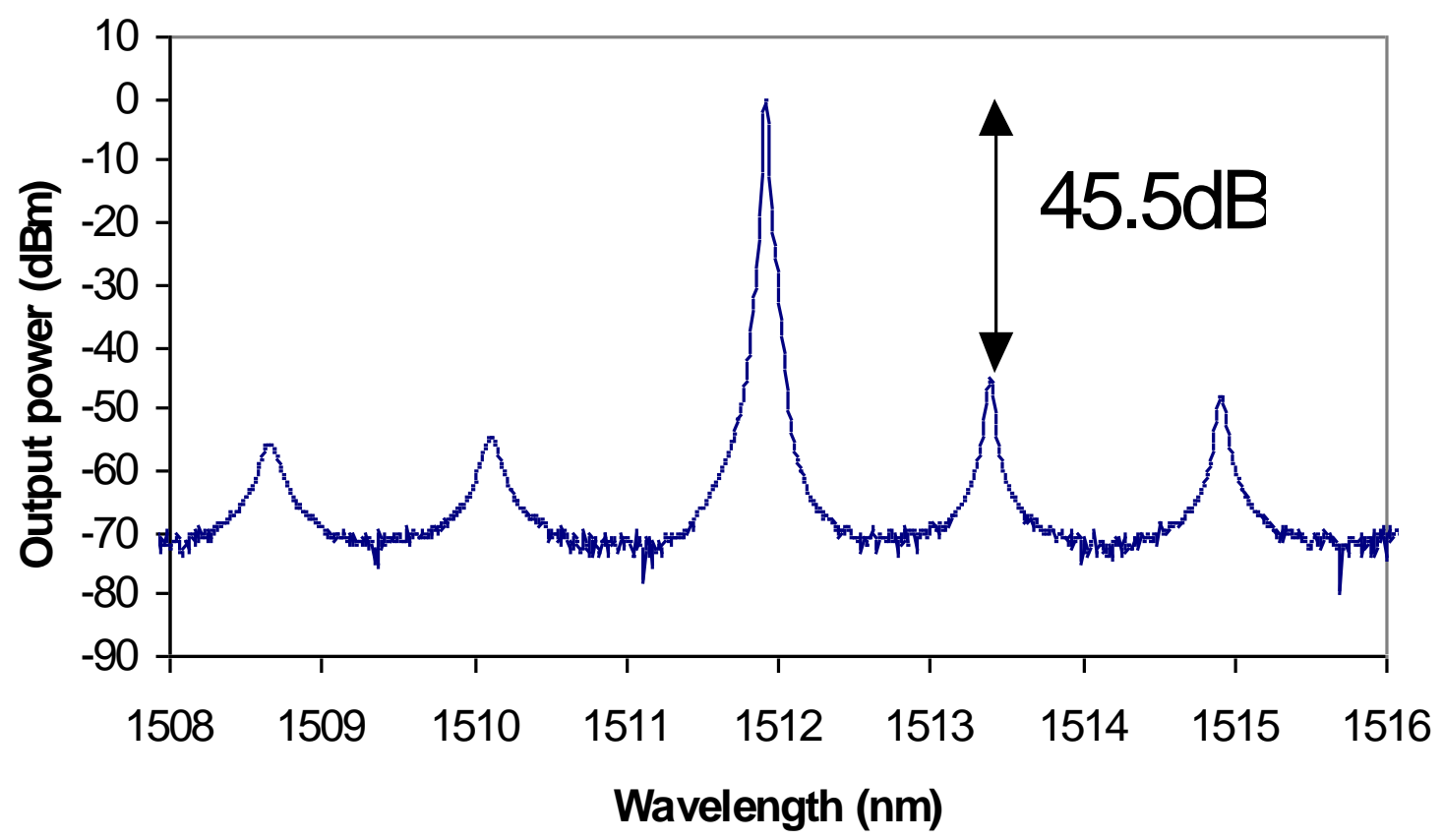

Fig. 13 


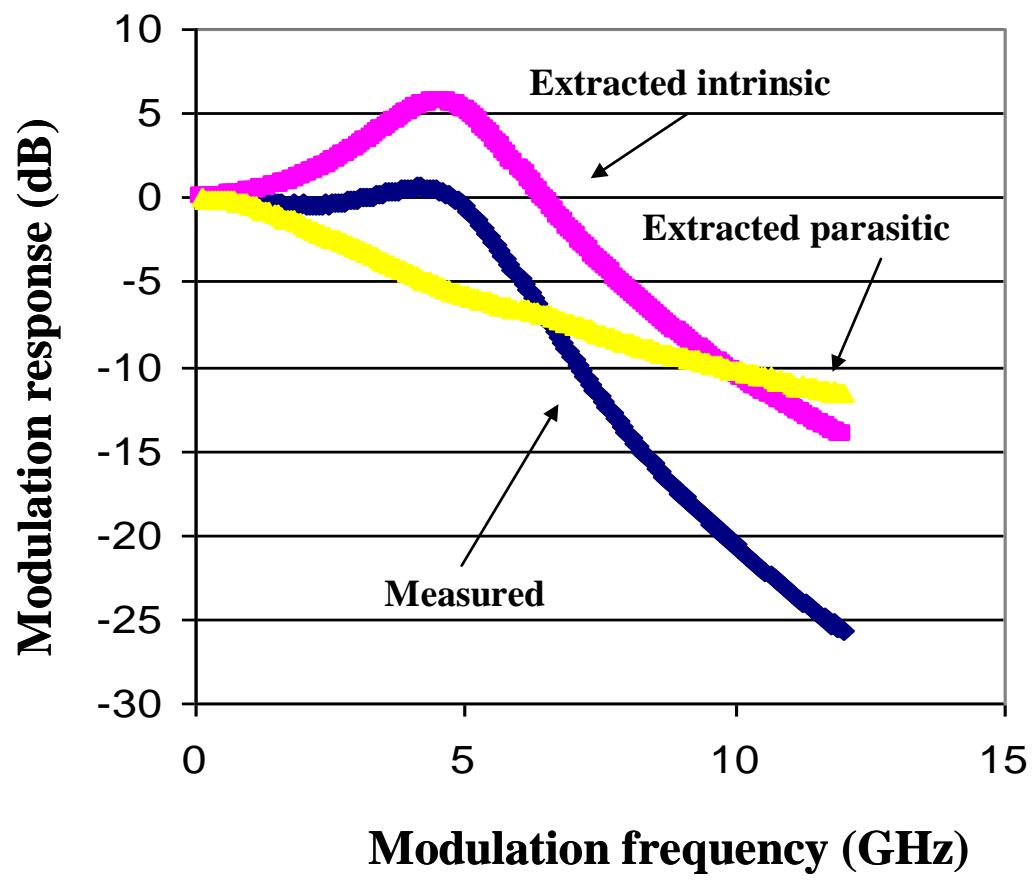

Fig. 14 


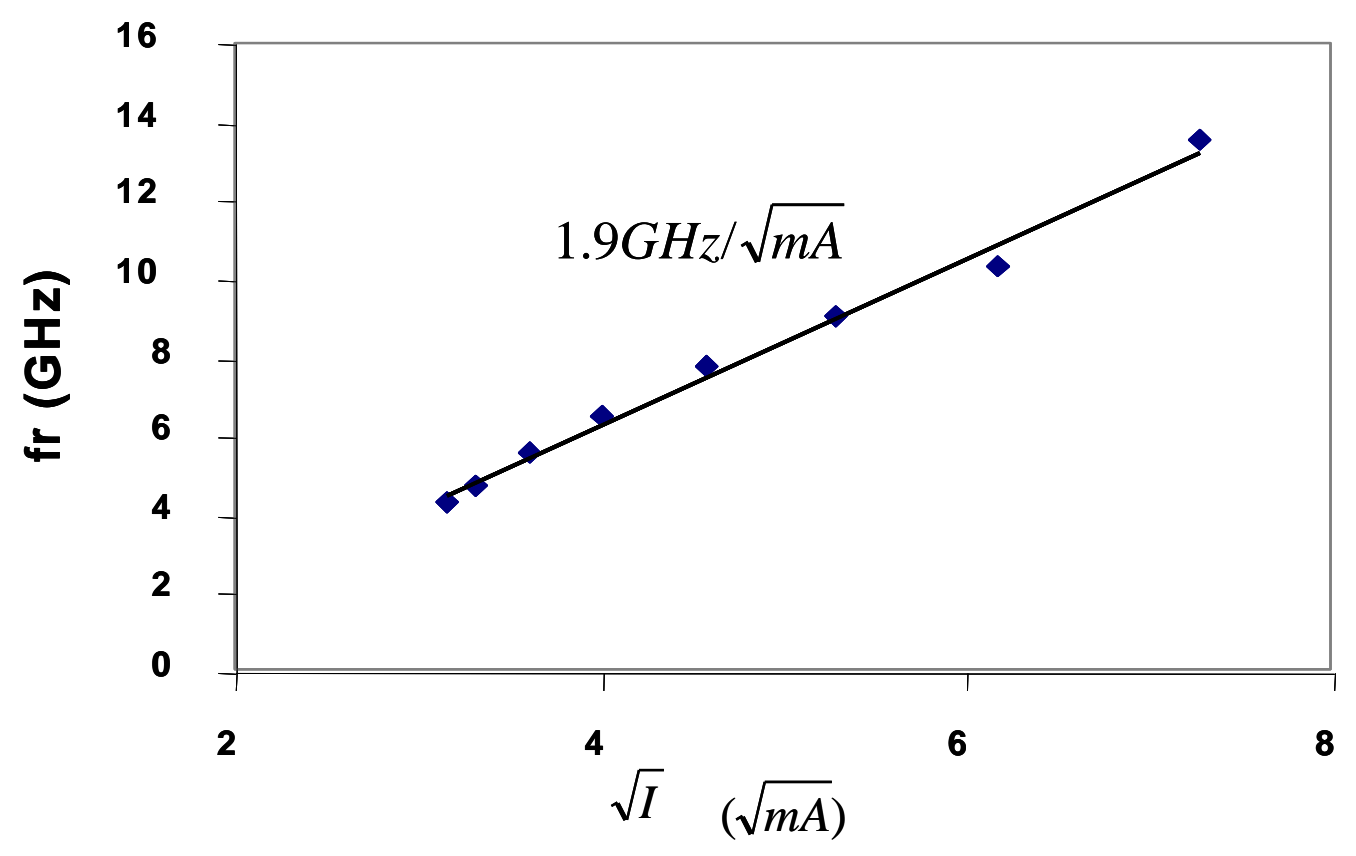

Fig. 15 


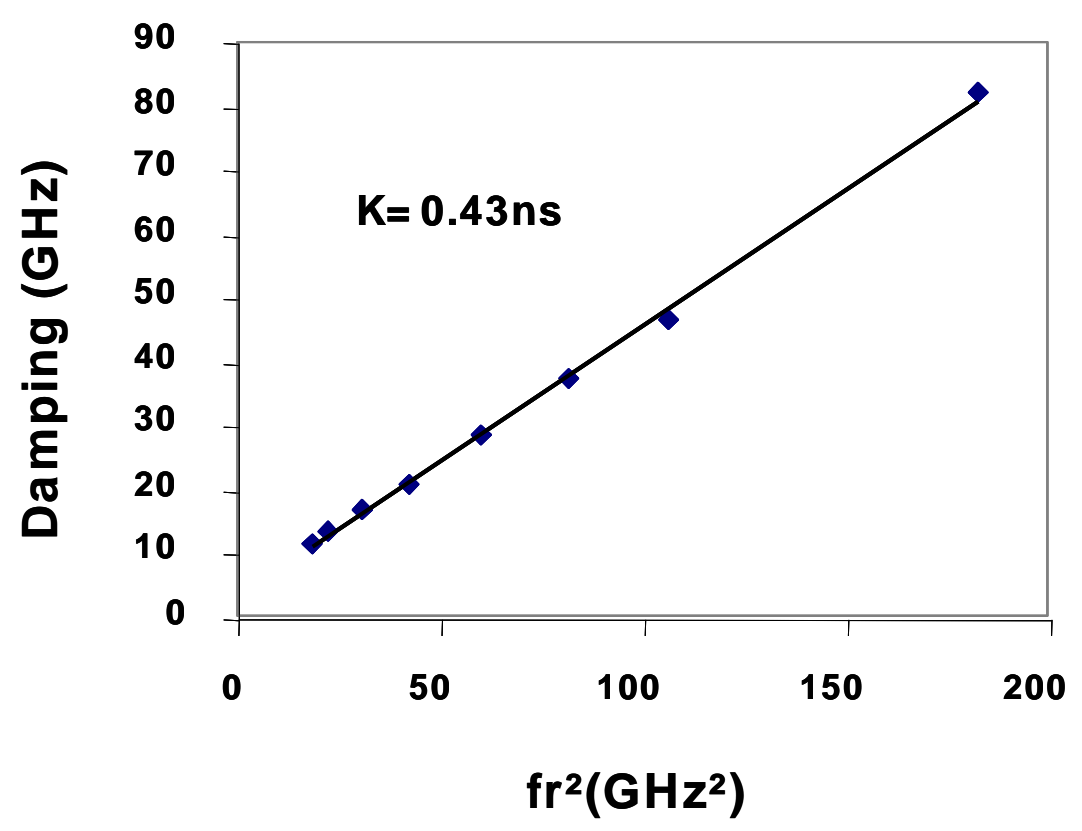

Fig. 16 


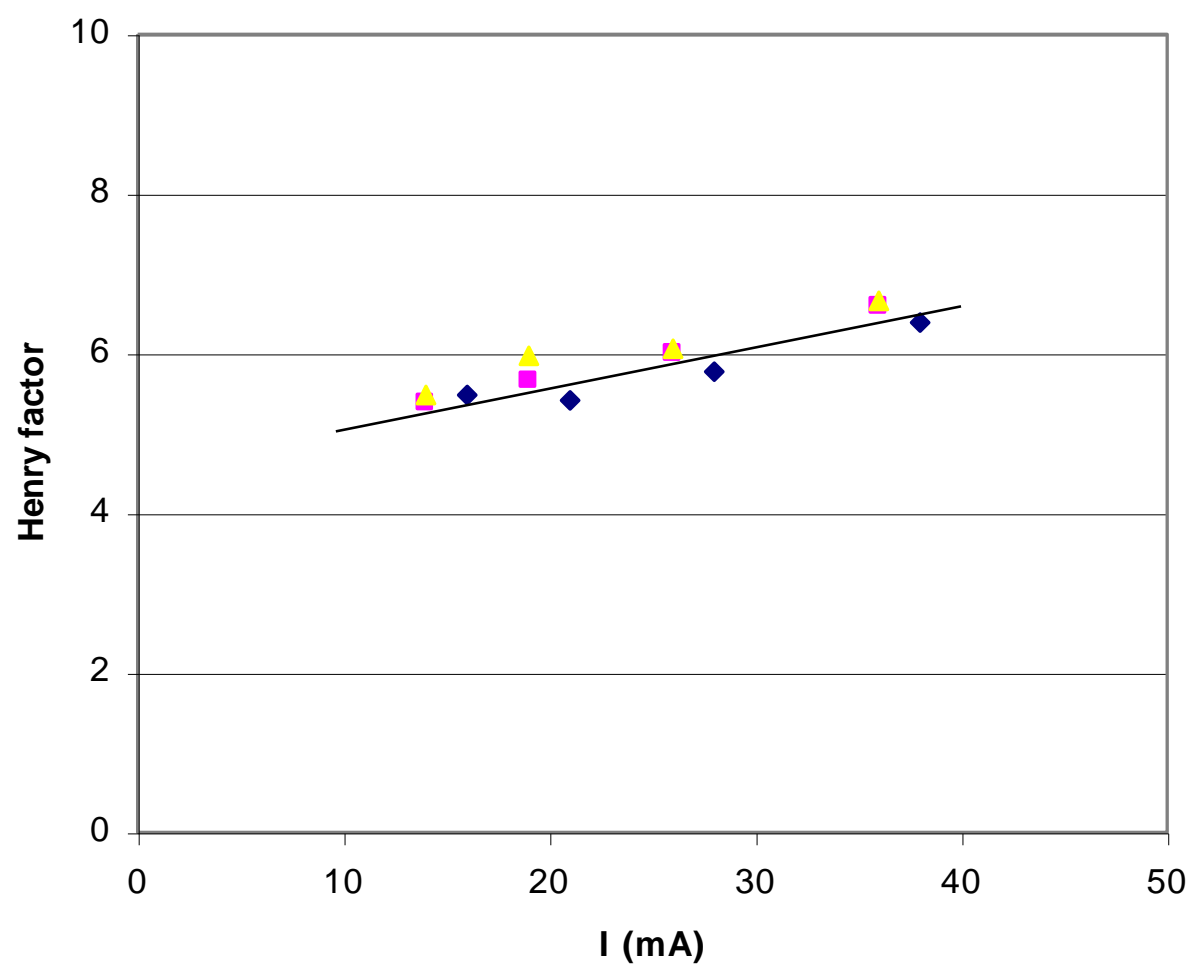

Fig. 17

- 34 - 


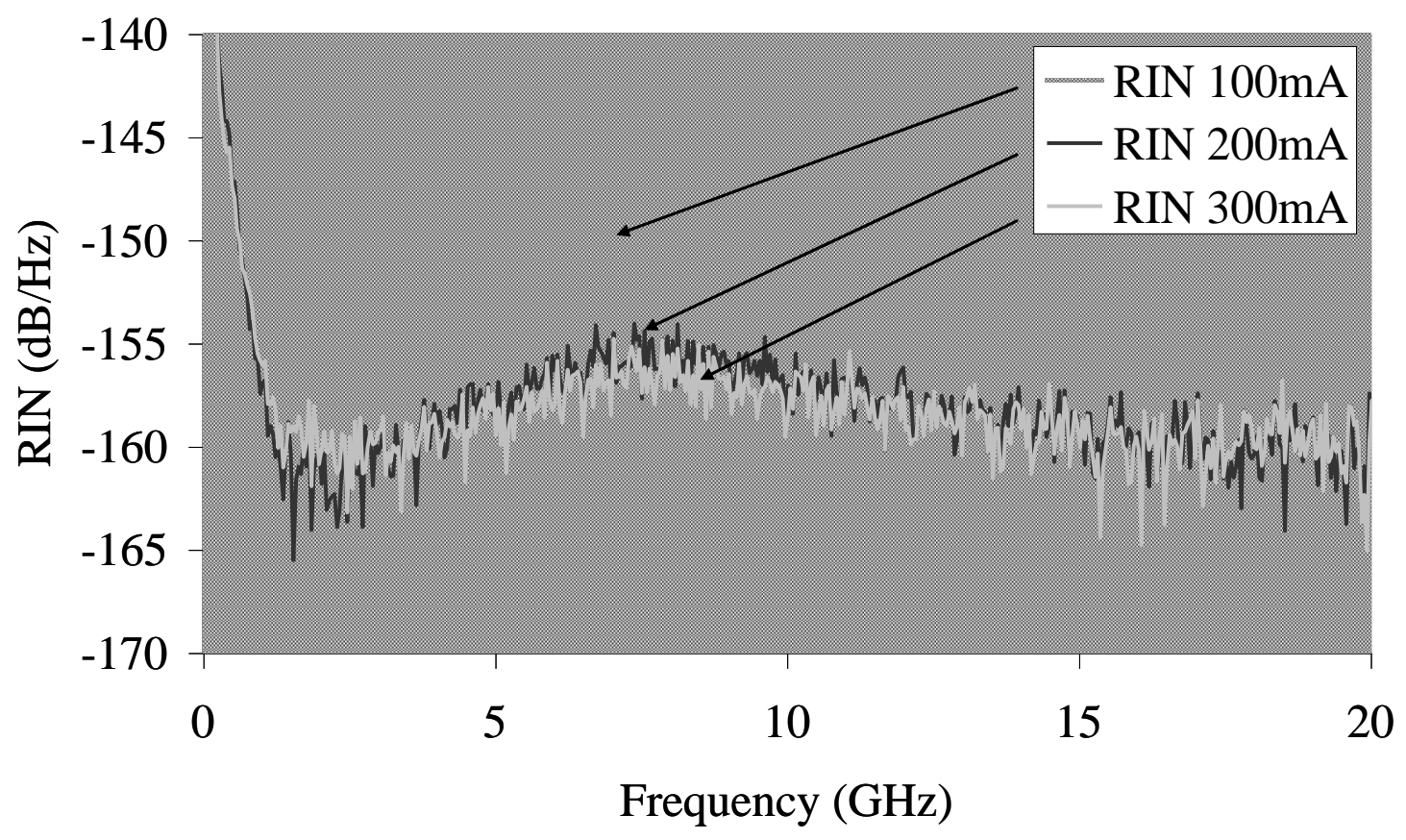

(a)

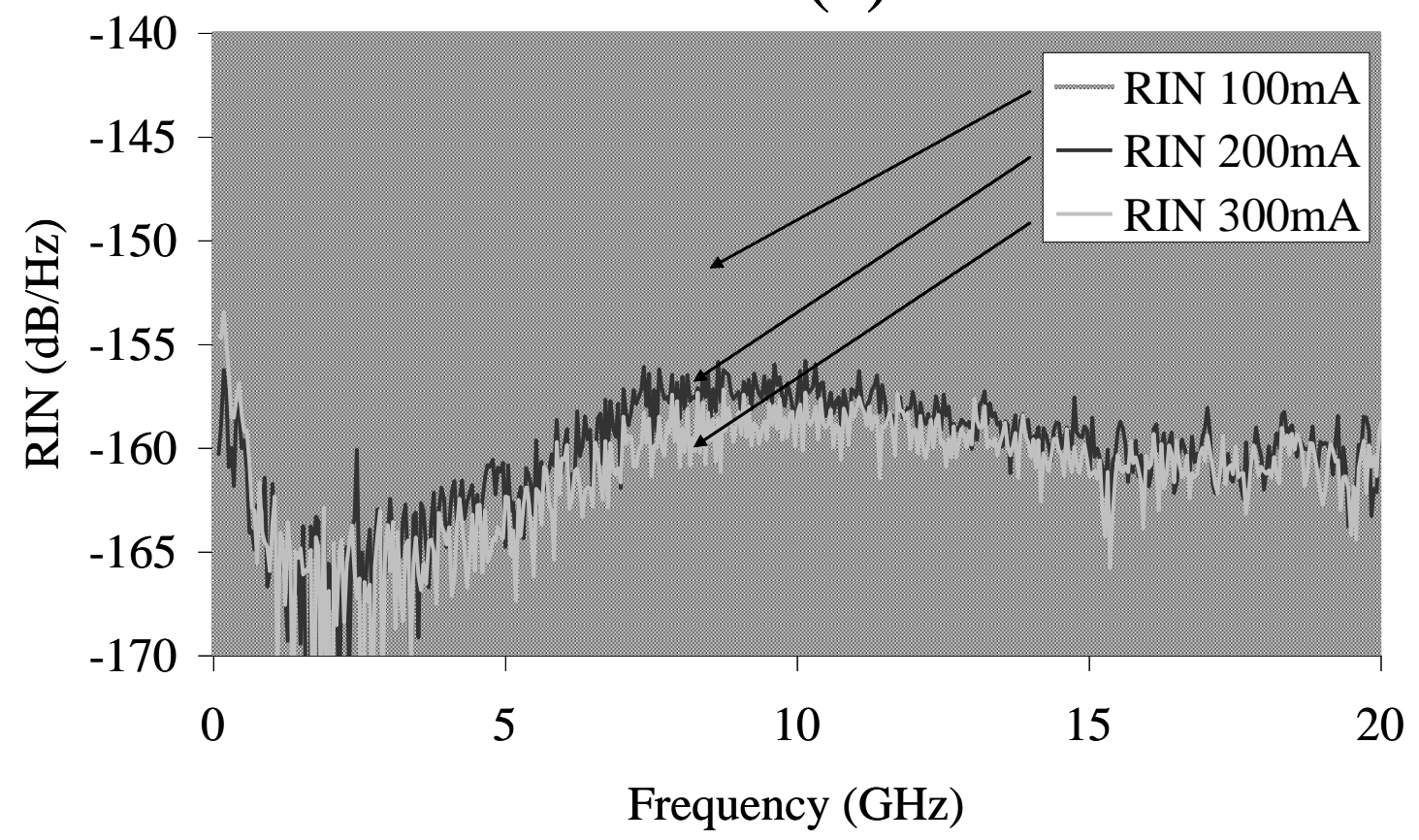

(b)

Fig. 18 


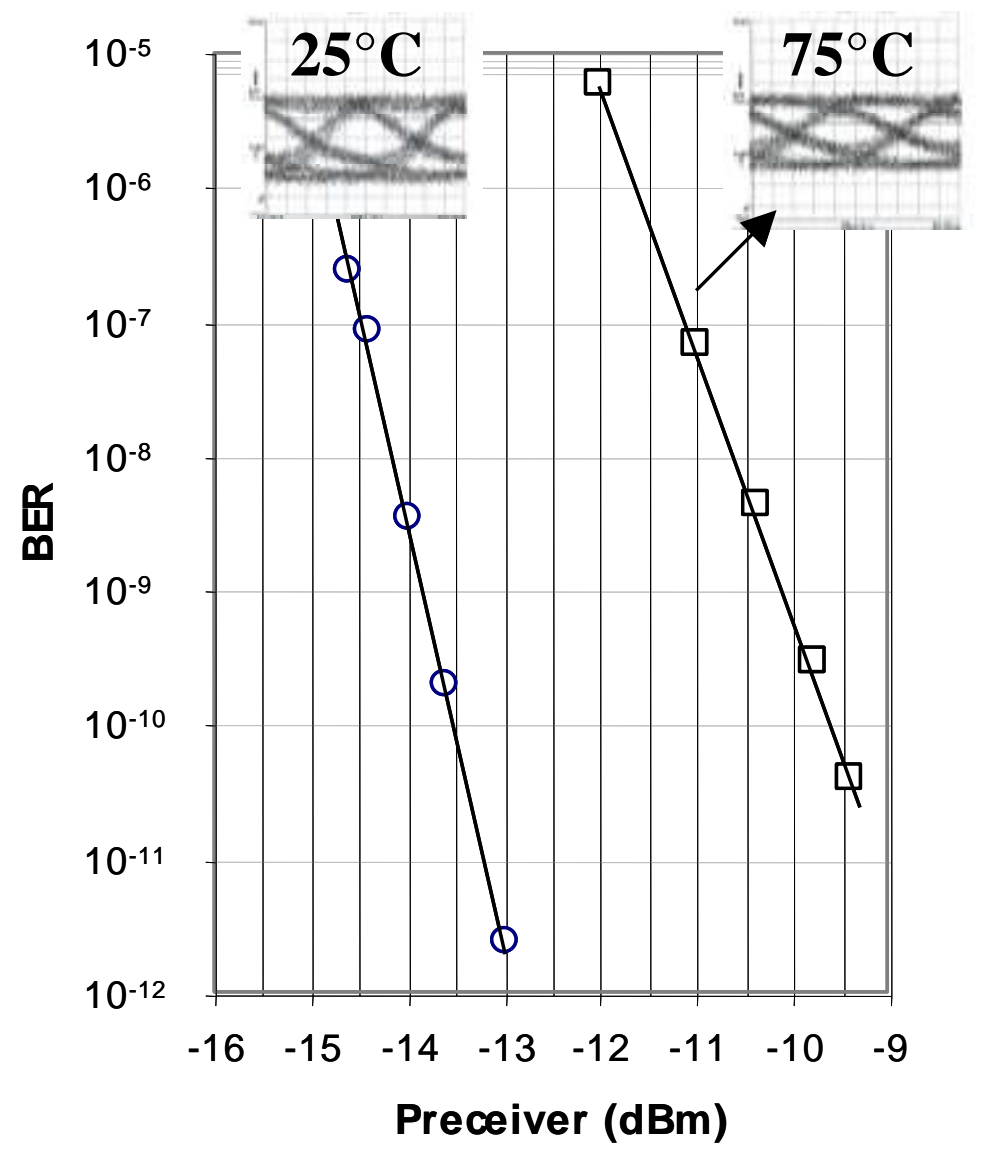

Fig. 19 


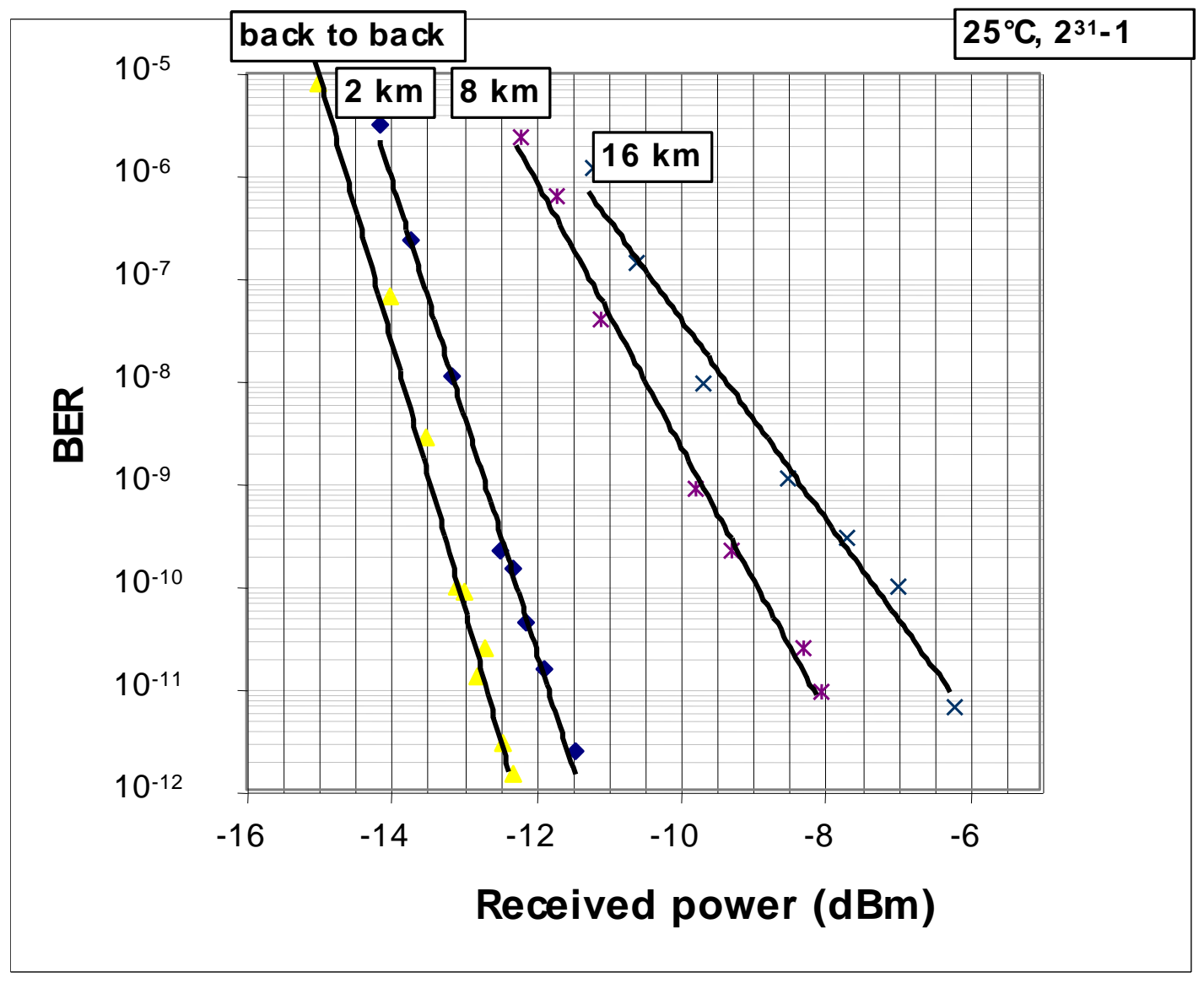

Fig. 20 


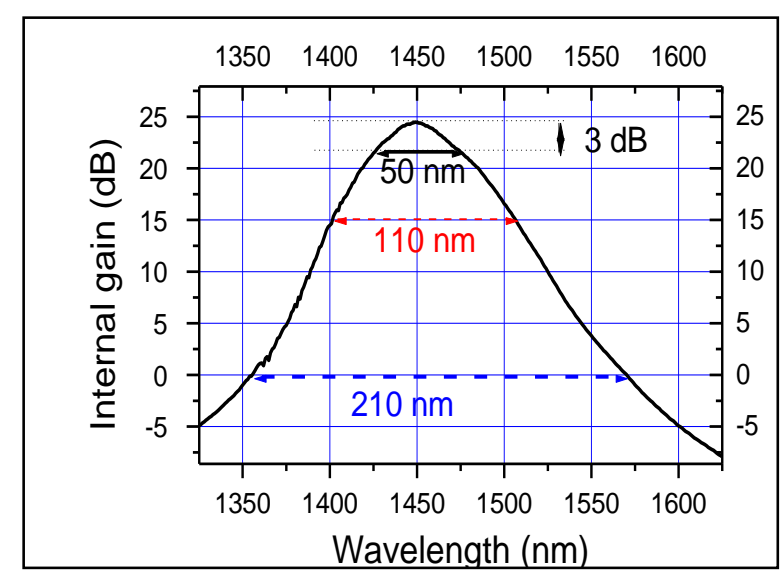

Fig. 21 


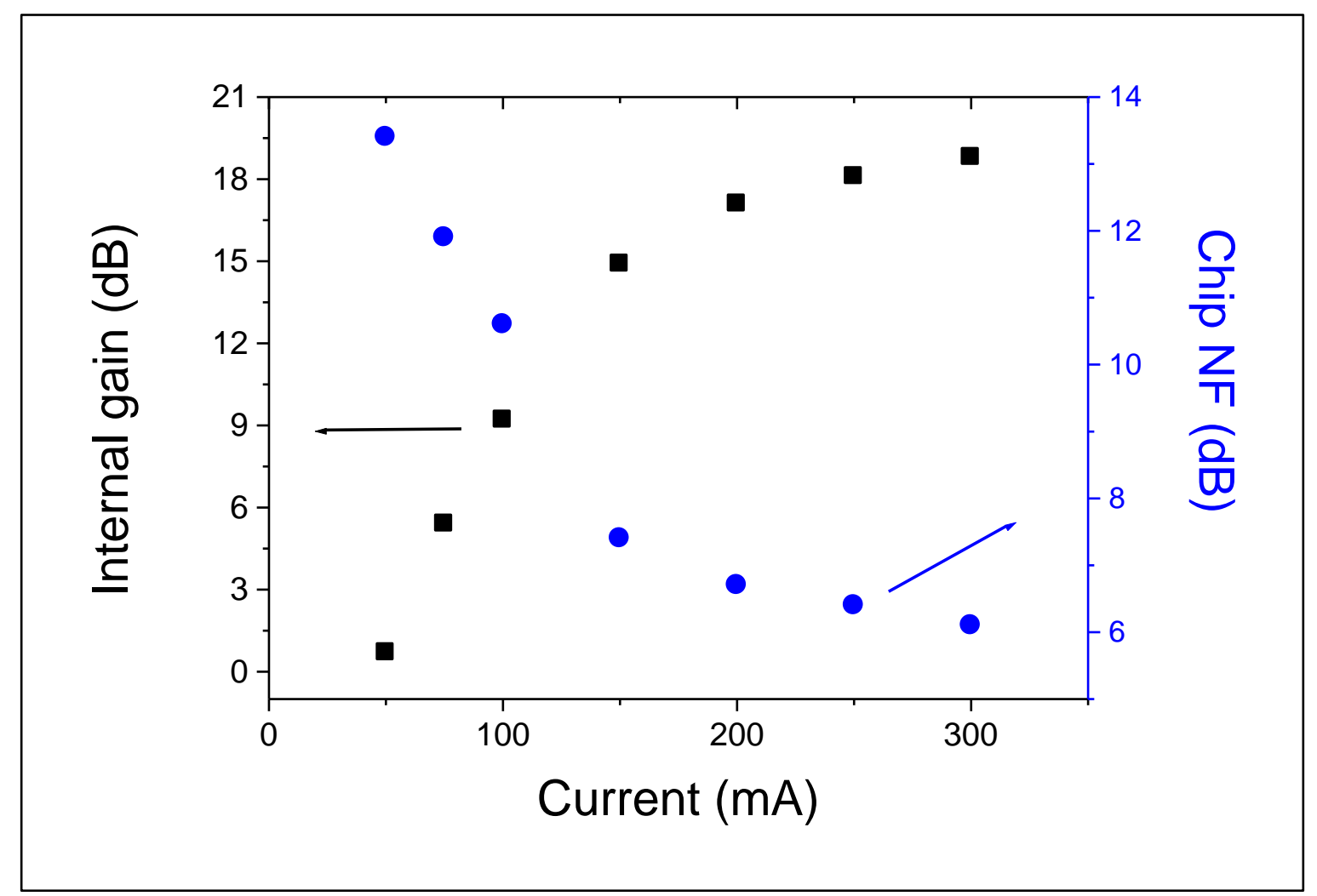

Fig. 22 


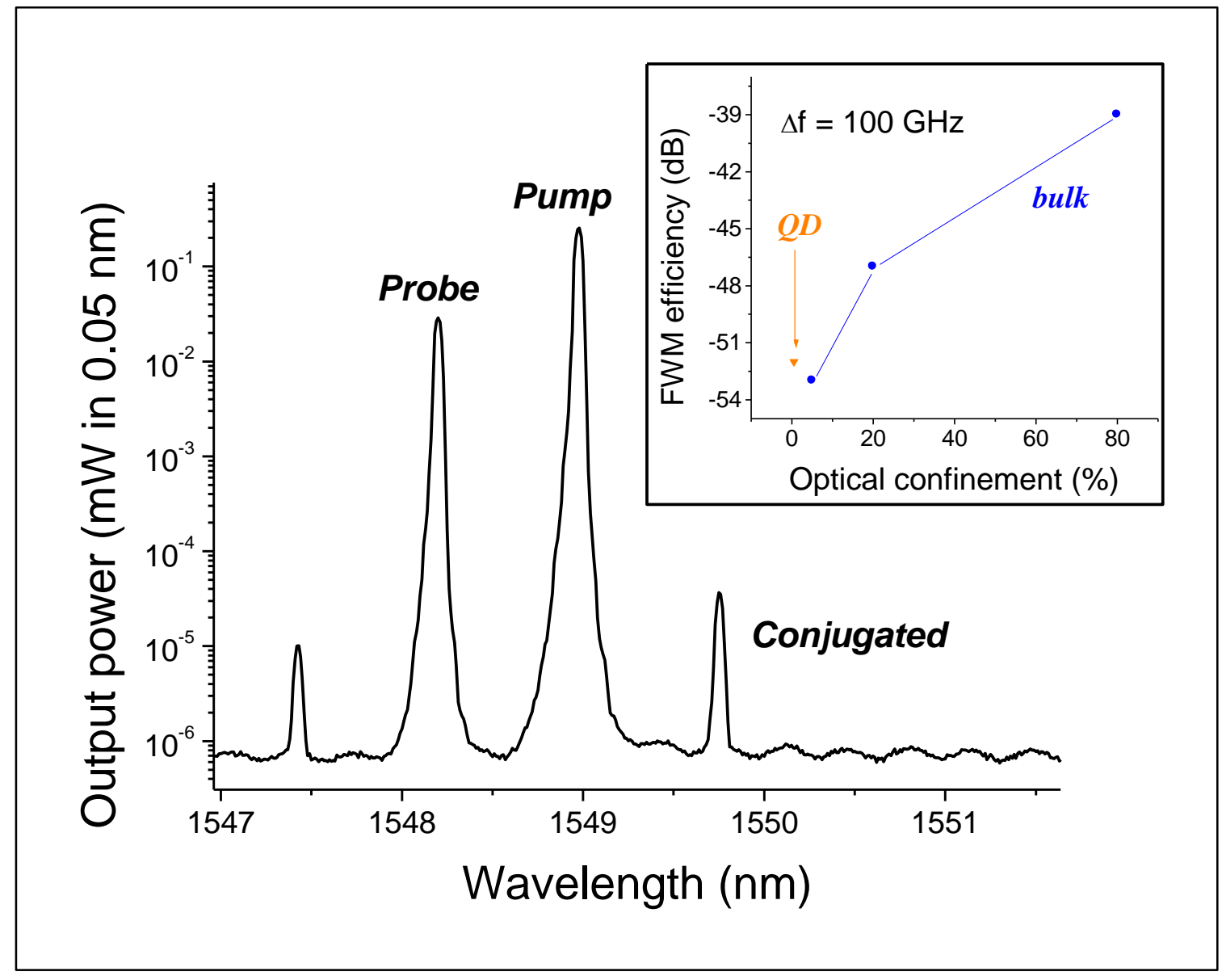

Fig. 23 


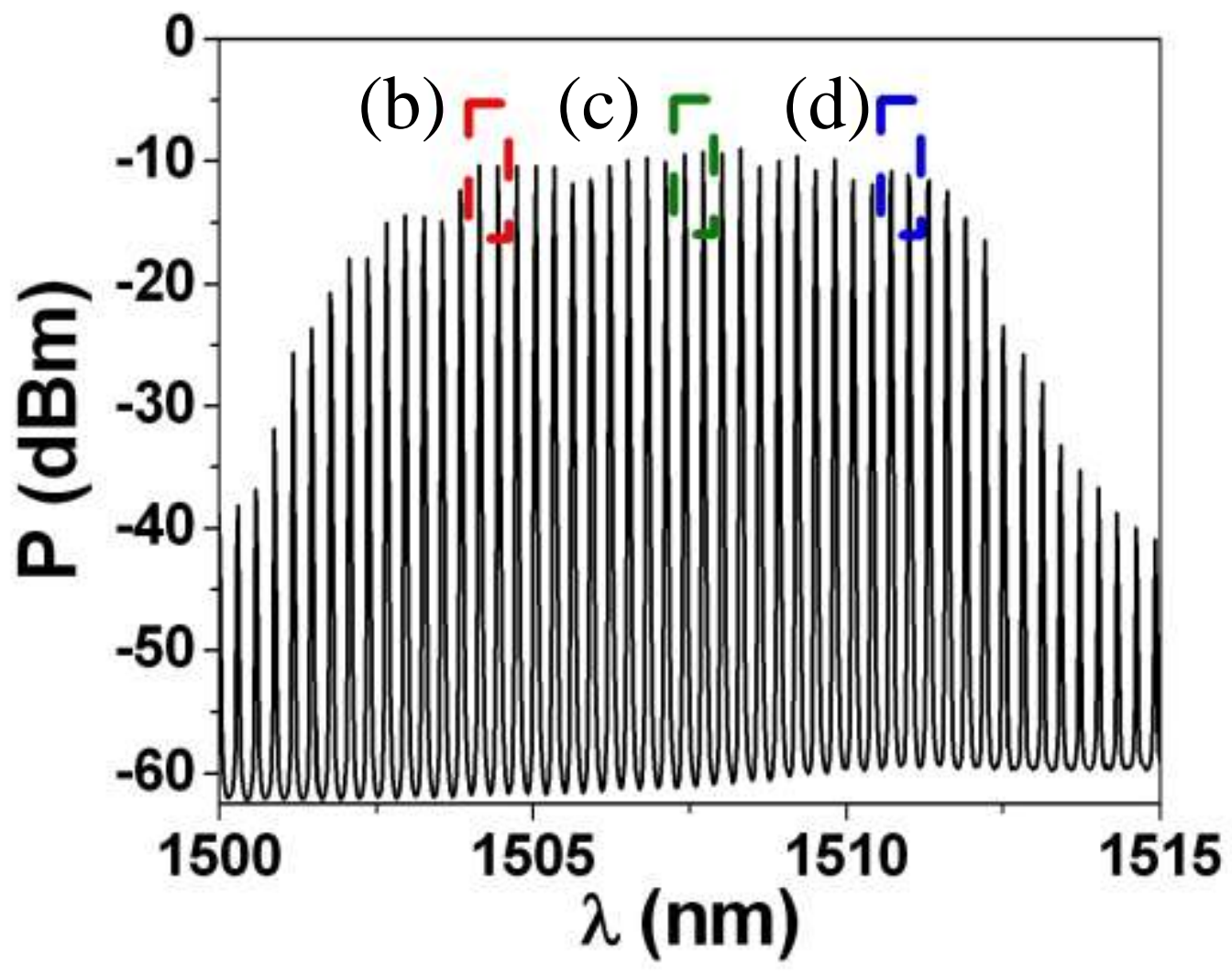

Fig. 24 

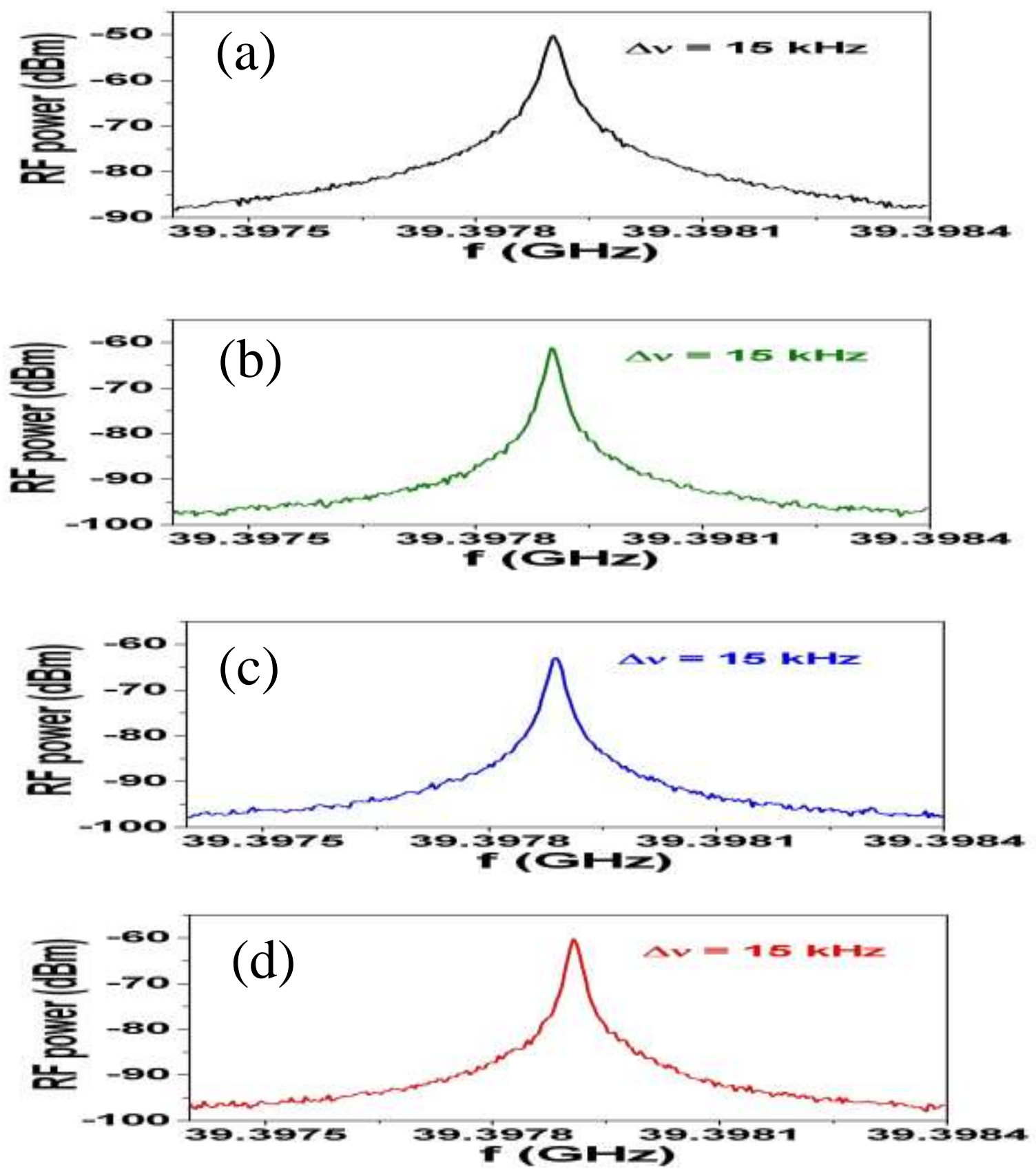

Fig. 25 


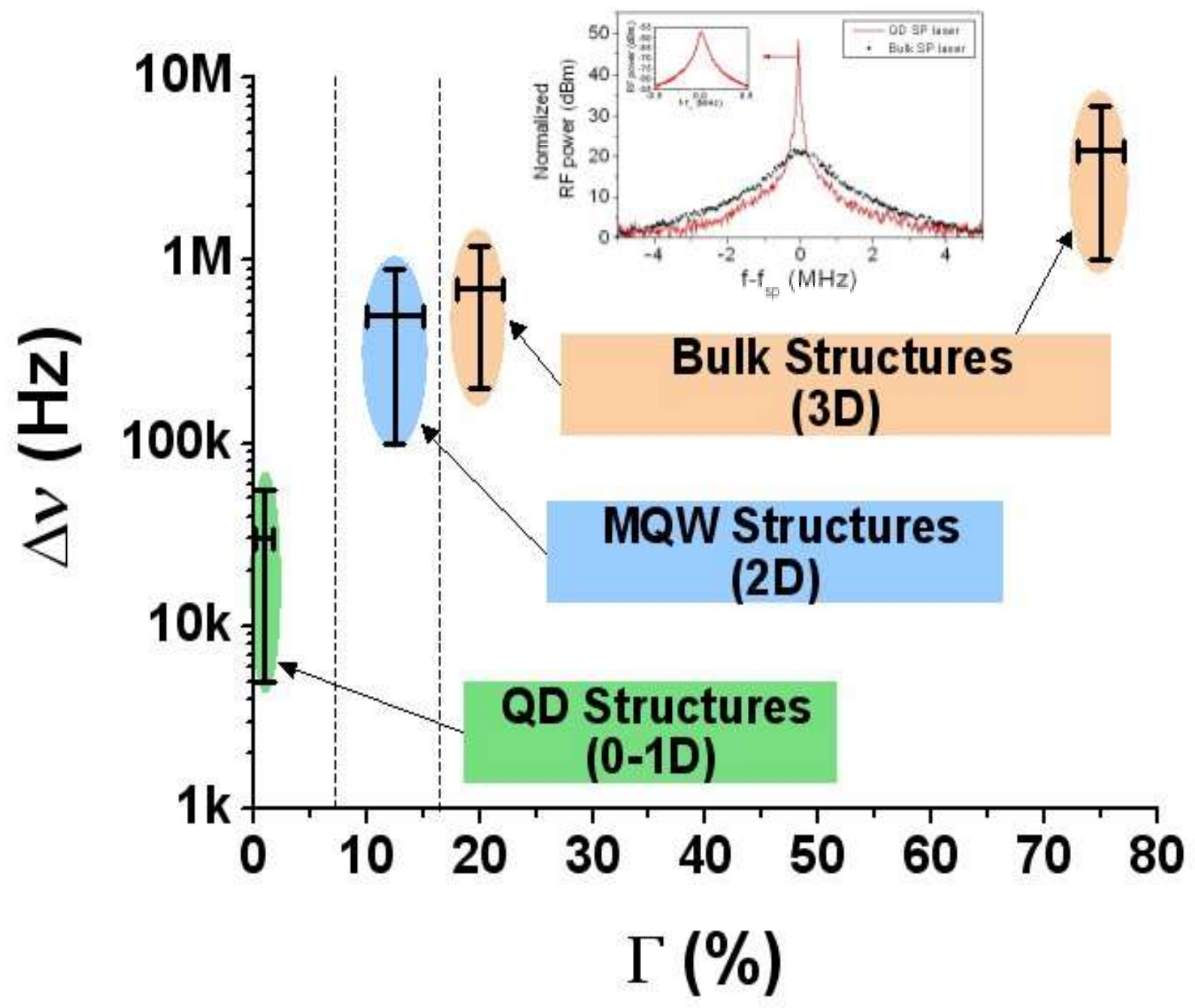

Fig. 26 

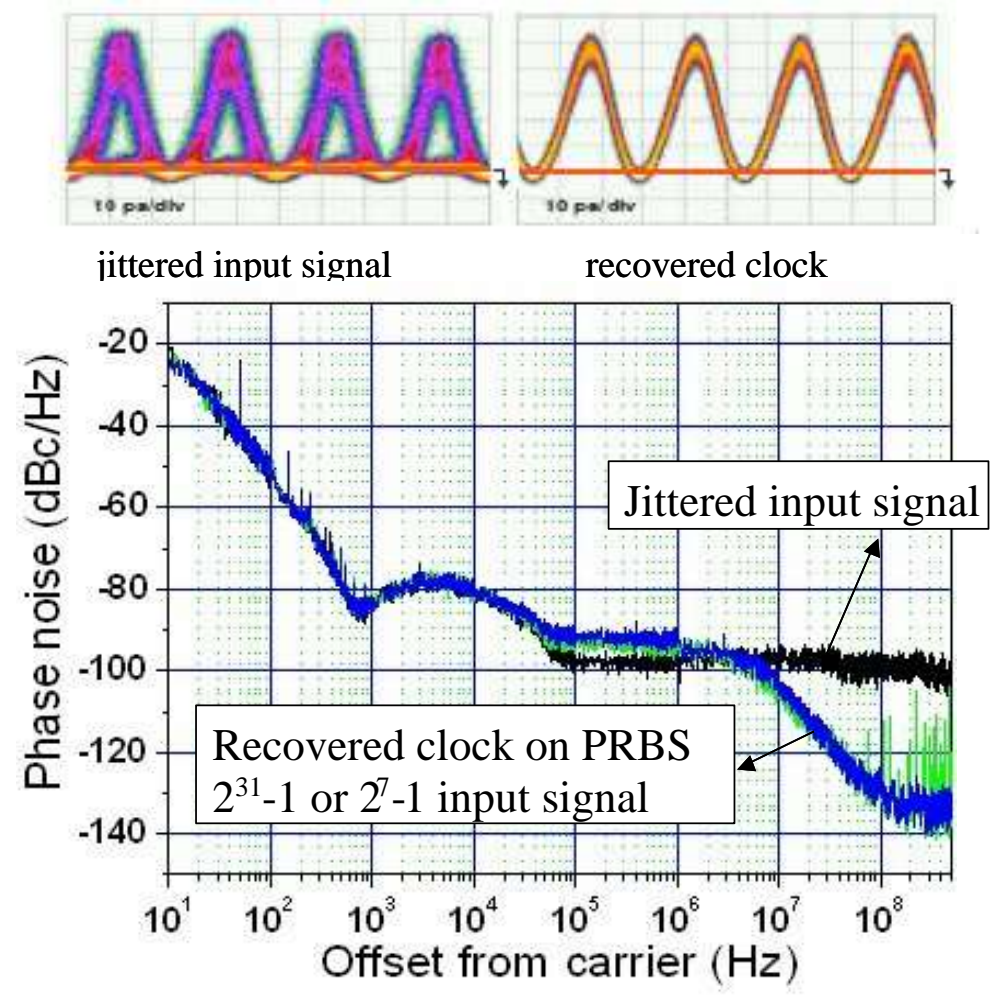

Fig. 27 


\section{REFERENCES}

1 D. Bimberg, M. Grundmann, and N. N. Ledentsov, “Quantum-Dot heterostructures,” John Wiley \& Sons, 1999

2 D. Bimberg N. Kirstaedter, N. N. Ledentsov, Zh. I. Alferov, P. S. Kop'ev, and V. M. Ustinov, "InGaAs-GaAs Quantum-Dot Lasers,” IEEE J. of Select. Topics in Quant. Electron., vol. 3, N², pp.196-205, 1997

3 M. Sugawara, K. Mukai, Y. Nakata, K. Otsubo, and H. Ishilkawa, "Performance and physics of quantum-dot lasers with self-assembled columnar-shaped and 1.3- $\mu \mathrm{m}$ emitting InGaAs quantum dots", IEEE J. of Select. Topics in Quant. Electron., vol. 6, pp. 462-474, 2000

4 J. P. Reithmaier and A. Forchel, "Single-mode distributed feedback and microlasers based on quantum-dot material", IEEE J. of Select. Topics in Quant. Electron., vol. 8, N5, pp.1035-1044, 2002

5 C. Paranthoen, N. Bertru, O. Dehaese, A. Le Corre, S. Loualiche, B. Lambert and G. Patriarche, "Height dispersion control of InAs/InP quantum dots emittingat 1.55mm,” Appl. /Phys. Lett., vol. 78, pp. 1751-1753, March 2001

6 H. Saito, K. Nischi and S. Sugou," Ground state lasing at room temperature in long-wavelength InAs quantum-dot lasers on InP (311)B substrates," Appl. Phys. Lett., vol. 78, pp. 267, 2001

7 R.H. Wang A. Stintz, P. M. Varangis, T. C. Newell, H. Li, K. J. Malloy, and L. F. Lester, "Room-Temperature Operation of InAs Quantum-Dash Lasers on InP (001),” IEEE Photon. Techn. Lett., Volume 13, Issue 8, Page(s):767 769, Aug. 2001

8 Jin Soo Kim; Jin Hong Lee; Sung Ui Hong; Won Seok Han; Ho-Sang Kwack; Chul Wook Lee; Dae Kon Oh, “Roomtemperature operation of InP-based InAs quantum dot laser," IEEE Photon. Techn. Lett, Volume 16, Issue 11, page 16071609, July 2004

9 W. Kaiser, K. Mathwig, S. Deubert, J.P. Reithmaier, A. Forchel, O. Parillaud, M. Krakowski, D. Hadass, V. Mikhelashsvili and G. Eisenstein, "Static and dynamic properties of laterally coupled DFB lasers based on InAs/InP Qdash structures,” Electron. Lett., Vol. 14, N¹4, 7th July 2005

10 F. Lelarge, B. Rousseau, B. Dagens, F. Poingt, F. Pommereau and A. Accard, "Room temperature continuous-wave operation of buried ridge stripe lasers using InAs/InP (100) quantum dots as active core," IEEE Photon.Techn. Lett., Vol. 17, Issue 7, pp1369 - 1371, July 2005

11 F. Lelarge, B. Rousseau, F. Martin, F. Poingt, L. Le Gouezigou, F. Pommereau, A. Accard, D. Make, O. Le Gouezigou, J. Landreau, J.G. Provost, J. Renaudier, G.H. Duan and B. Dagens, "Buried ridge stripe lasers using InAs/InP (100) quantum dashes based active layer: a step towards low noise sources for high-speed direct modulation," International Conference on Indium Phosphide and Related Materials, Conference Proceedings, Page(s) 127-130, May 2006

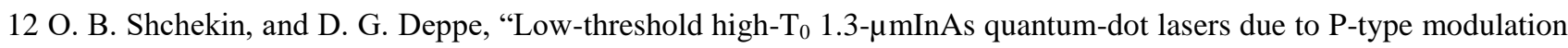
doping of the active region”, IEEE Photon. Techn. Lett., Volume 14, Pages 1231 - 1233, Sept. 2002

13 D. G. Deppe, H. Huang, and O. B. Shchekin, "Modulation characteristics of quantum-dot lasers: the influence of Ptype doping and the electronic density of states on obtaining high speed", IEEE J. Quantum. Electron., vol. 38, pp. 15871593, Dec. 2002

14 Y. Li, T.J. Rotter, Y. Xin, A. Stintz, A. Martinez, K.J. Malloy, L.F. Lester, “ High characteristic temperature of pdoped InAs quantum dots-in-a-well lasers on InP substrate," CLEO’06, paper CThX6, 2006

15 H. C. Sun, L. Davis, S. Sethi, J. Singh, and P. Bhattacharya, "Properties of a tunneling injection quantum well laser: recipe for a cold device with a large modulation bandwidth", IEEE Photon. Tech. Lett., vol. 5, pp. 870-872, 1993 
16 Z. Mi, J. Yang, and P. Bhattacharya, "High performance p-doped InAs tunnel injection quantum dash lasers on InP", Proceedings IPRM2006, TuA1.2, 2006

17 E. U. Rafailov, M. A. Cataluna, W. Sibbett, N. D. Il'inskaya, Yu. M. Zadiranov, A. E. Zhukov, V. M. Ustinov, D. A. Livshits, A. R. Kovsh and N. N. Ledentsov, "High-power picosecond and femtosecond pulse generation from a twosection mode-locked quantum-dot laser", Appl.Phys. Lett., vol. 87, 081107, 2005

18 M.-T. Choi, W. Lee, J.-M. Kim, and P. J. Delfyett, "Ultrashort, high-power pulse generation from a master oscillator power amplifier based on external cavity mode-locking of a quantum-dot two-section diode laser", Appl.Phys. Lett., vol. $87,221107,2005$

19 Zhang, L.; Cheng, L.; Gray, A.L.; Luong, S.; Nagyvary, J.; Nabulsi, F.; Olona, L.; Sun, K.; Tumolillo, T.; Wang, R.; Wiggins, C.; Zilko, J.; Zou, Z.; Varangis, P.M.; Su, H.; Lester, L.F.;"Low timing jitter, $5 \mathrm{GHz}$ optical pulses from monolithic two-section passively mode-locked $1250 / 1310 \mathrm{~nm}$ quantum dot lasers for high-speed optical interconnects", Optical Fiber Communication Conference, 2005. Technical Digest. OFC/NFOEC, Volume 3, 6-11 Page(s):3 pp. Vol. 3, March 2005

20 K. Sato, "Optical pulse generation using Fabry-Perot lasers under continuous wave operation", IEEE Journal of Selected Topics in Quantum Electronics, vol. 9, pp. 1288--1293, 2003

21 J. Renaudier, G-H. Duan, J-G. Provost, H. Sillard-Debregeas, P. Gallion, "Phase correlation between longitudinal modes in semiconductor self-pulsating DBR lasers", IEEE Photonics Technol. Lett., vol. 17, pp. 741-743, 2005

22 J. Renaudier, R. Brenot, B. Dagens, F. Lelarge, B. Rousseau, F. Poingt, O. Legouezigou, F. Pommereau, A. Accard, P. Gallion and G.-H. Duan, " $45 \mathrm{GHz}$ self-pulsation with narrow linewidth in quantum dot Fabry-Perot semiconductor lasers at $1.5 \mu \mathrm{m}, ”$ Electron. Lett., Vol. 41, $\mathrm{N}^{\circ} 18$, Sept. 2005

23 C. Gosset, K. Merghem, A. Martinez, G. Moreau, G. Patriarche, G. Aubin, J. Landreau, F. Lelarge and A. Ramdane, "Subpicosecond pulse generation at $134 \mathrm{GHz}$ and low radiofrequency spectral linewidth in quantum dash-based FabryPerot lasers emitting at $1.5 \mu \mathrm{m}$," Electron. Lett., Vol.42, N², Jan. 2006

24 J. Renaudier, B. Lavigne, M. Jourdran, P. Gallion, F. Lelarge, B. Dagens, A. Accard, O. Legouezigou and G.H. Duan, "First demonstration of all-optical clock recovery at $40 \mathrm{GHz}$ with standard compliant jitter characteristics based on a quantum-dots self-pulsating semiconductor laser," ECOC'05, postdeadline paper Th 4.3.4, 2005

25 J. Renaudier, B. Lavigne, P. Gallion, F. Lelarge, B. Dagens, O. Legouezigou and G.-H. Duan, "Standard-compliant jitter transfer function of an all-optical clock recovery at $40 \mathrm{GHz}$ based on a quantum-dots self-pulsating semiconductor laser”, IEEE Photon. Techn. Lett., Volume 18, Pages 1249 - 1251, Sept. 2006

26 J. Renaudier, B. Lavigne, P. Gallion and G.-H. Duan, "Study of phase noise properties and timing jitter of $40 \mathrm{GHz}$ all optical clock recovery using self-pulsating semiconductor lasers", to appear in J. Lightwave Technol

27 S. L. Chuang, "Physics of optoelectronic devices", John Wiley \& Sons, 1995

28 B. Dagens, A. Markus, J.X. Chen, J.-G. Provost, D. Make, O. Le Gouezigou, J. Landreau, A. Fiore and B. Thedrez, "Giant Linewidth Enhancement Factor and Purely Frequency Modulated Emission from a Quantum Dot Laser", Electron. Lett., vol. 41, N 6 , pp323-324, $17^{\text {th }}$ March 2005

29 G. Moreau, K. Merghem, D. Cong, G. Patriarche, F. Lelarge, F.; B. Rousseau; B. Dagens, F. Poingt, A. Accard, F. Pommereau, A. Ramdane, "High Modal Gain 9- and 12- Layer InAs/InP Quantum Dash Lasers Emitting at $1.55 \mu \mathrm{m}$ ", International Conference on Indium Phosphide and Related Materials, Conference Proceedings, Page(s):411 - 414 May 2006

30 I. P. Marko et al, "Carrier transport and recombination in p-doped and intrinsic $1.3 \mu \mathrm{m}$ InAs/GaAs quantum-dot lasers”, Appl. Phys. Lett., vol. 87, pp. 211114, 2005

31 R. Nagarajan,; T. Fukushima, M. Ishikawa, J.E. Bowers, R.S.Geels and L.A Coldren, "Transport limits in high-speed quantum-well lasers: experiment and theory" IEEE Photonics Technology Letters, Volume 4, Issue 2, Page(s):121-123, Feb. 1992 
32 G. Moreau, K. Merghem, A. Martinez, F. Lelarge, A. Ramdane, "Low Linewidth Enhancement Factor $\left(\alpha_{H} \sim 0.5\right)$ of 9- Layer InAs/InP Quantum Dash Lasers Emitting at $1.55 \mu \mathrm{m}$ ”, International Conference on Indium Phosphide and Related Materials, Conference Proceedings, Page(s):116 - 118 May 2006

33 J. E. Bowers, W. T. Tsang, T. L. Koch, N. A. Olsson, and R. A. Logan, "Microwave intensity and frequency modulation of hetero-epitaxial-ridge-overgrown distributed-feedback lasers", Appl. Phys. Lett., vol. 46, pp. 233-235, Feb. 1985

34 T. Fukushima, R. Nagarajan, J.E.Bowers, R.A. Logan and T. Tanbun-Ek, "Relative intensity noise reduction in InGaAs/InP multiple quantum well lasers with low nonlinear damping", IEEE Photonics Technology Letters, Volume 3, Issue 8, Pages 688 - 693, Aug. 1991

35 B. Dagens, F. Lelarge, L. Morel, D. Make, B. Rousseau, O. Le Gouezigou, J.-G. Provost, F. Poingt, L. Le Gouezigou, F. Pommereau, J. Landreau, A. Accard, and B. Thedrez, "10 Gb/s InAs/InP(001) Quantum Dot Lasers Operation on CBand up to $75^{\circ} \mathrm{C}$," ECOC'05, paper We4.P003, Glasgow, 2005

36 D. Hadass, A. Bilenca, R. Alizon, H. Dery, V. Mikhelashvili, G. Eisenstein, R. Schwertberger, A. Somers, J.P. Reithmaier, A. Forchel, M. Calligaro, S. Bansropun and M. Krakowski,, "Gain and noise saturation of wide-band InAs-InP quantum dash optical amplifiers: model and experiments," IEEE J. of Select. Topics in Quant. Electron., vol.11, N5, Sept/Oct. 2005, pp1015-1024

37 R. Alizon, D. Hadass, V. Mikhelashvili, G. Eisenstein, R. Schwertberger, A. Somers, J.P. Reithmaier, A. Forchel, M. Calligaro, S. Bansropun and M. Krakowski, "Multiple wavelength amplification in wide band high power $1550 \mathrm{~nm}$ quantum dash optical amplifier,” Electron. Lett., Vol.40, N¹2, Jun. 2004

38 T. Akiyama, M. Ekawa, M. Sugawara, K. Kawaguchi, H. Sudo, H. Kuwatsuka, H. Ebe, A. Kuramata, and Y. Arakawa, "Quantum dots for semiconductor optical amplifiers", Optical Fiber Communication Conference, 2005. Technical Digest. OFC/NFOEC, paper OWM2, March 2005

39 T. Briant, P. Grangier, R. Tualle-Brouri, A. Bellemain, R. Brenot and B. Thédrez, "Accurate determination of the noise figure of polarization dependent optical amplifiers: theory and experiment", Journal of Lightwave Technol., vol. 24, pp. 1499-1503, Mar. 2006

40 A. Borghesani, N. Fensom, A. Scott, G. Crow, L. Johnston, J. King, L. Rivers, S. Cole, S. Perrin, D. Scrase, G. Bonfrate, A. Ellis, I. Lealman, G. Crouzel, L. H. K. Chun, A. Lupu, E. Mahe, P. Maigne, "high saturation power ( $>16.5$ $\mathrm{dBm})$ and low noise figure $(<6 \mathrm{~dB})$ semiconductor optical amplifier for C-band operation", Optical Fiber Communication Conference, Technical Digest. OFC/NFOEC, paper ThO1, 2003. 
François Lelarge was born in France in 1966. He received the Diploma in material science in 1993 and the Ph. D degree in 1996, both from the University of Pierre et Marie Curie, Paris, France. From 1993 to 1996, he was with the Laboratory of Microstructures and Microelectronic, CNRS Bagneux, France. His thesis work was devoted to the fabrication and the optical characterization of GaAs/AlAs lateral supperlattice grown on vicinal surfaces by MBE. From 1997 to 2000 , he was a post-doctoral Researcher at the Institute of Micro and Optoelectronics, Lausanne, Switzerland. He worked on InGaAs/GaAs quantum wires fabrication by MOCVD regrowth on patterned substrates. Presently, he is working within Alcatel Thales III-V Lab on InGaAsP/InP GSMBE growth for optoelectronic devices, in particular, on quantum dots based lasers and amplifiers.

Béatrice Dagens received the engineering degree in Physics and Chemistry from ESPCI, Paris, France in 1992. She obtained the $\mathrm{PhD}$ degree in Optoelectronic from the University Paul Sabatier, Toulouse, France in 1995, for her theoretical and experimental work on $0.8 \mu \mathrm{m}$ emitting MOPA (Master Oscillator Power Amplifier), integrating a DBR laser with a flared semiconductor optical amplifier (SOA). After one postdoctoral year in Politecnico di Torino, Italy, concerning the modelling of ultrafast dynamics in SOAs, she joined the optical component research department in Alcatel, Marcoussis, France. There, she worked first on SOA modelling and design applied to SOA based integrated devices. Then she became responsible for the design, the realisation and the measurement of SOA based interferometers for all-optical and high bit rate wavelength conversion and regeneration. Her current activity is focused on advanced laser diodes emitting at 1.3 and $1.55 \mu \mathrm{m}$. Since 1992, her research results have been recorded in 40 refereed papers, and 70 international conferences including two invited presentations. Besides she is co-author of 11 patents.

Jeremie Renaudier was born in Laval, France, on October 27, 1978. He received the B.S. degree from the Ecole Nationale Supérieure des Télécommunications (ENST-Bretagne), Brest, France, and the M.S. degree in optical communications and networks from the University de Bretagne Occidentale, Brest, France, both in 2002. He received the Ph.D. degree from the Ecole Nationale Supérieure des Télécommunications (ENST), Paris, France, in 2006. His Ph.D. thesis was focused on the functional mode-locked DBR lasers for telecommunications applications at $40 \mathrm{~Gb} / \mathrm{s}$ and beyond. He is now with Alcatel Research \& Innovation working on optical transmission systems.

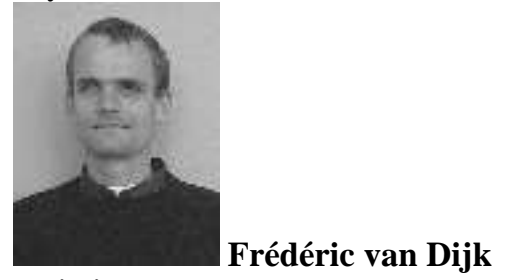

Frédéric van Dijk was born in Chevreuse, France, in 1972. He received the PhD degree from Université Paul Sabatier of Toulouse, France in 1999.

His PhD work, performed at LAAS-CNRS, Toulouse, dealt with growth, process and characterization of AlGaAs/GaAs VCSEL structures. In 2000 he joined THALES Research an Technology, Orsay, France. He is currently working at Alcatel-Thales III-V Lab on design, fabrication and characterisation of laser sources for microwave applications. He is in particular involved in studies on directly modulated DFB lasers, mode-locked lasers for frequency synthesis and clock recovery, and microwave photonic systems.

Jean LANDREAU was born in Libourne, France on june 28,1950. He graduated from the Concervatoire National des Arts et Metiers, Paris, in 1981.

From 1975 to 2001 he had been working on semiconductor laser technology in France Telecom R\&D. He joined Alcatel R\&I, on 2001, where he is currently in charge of laser facet optical Coatings and fiber tip lensing in Alcatel-Thales III-V Lab, Palaiseau, France.

Olivier Drisse was born in Nancy, France in 1969. He received a Ph.D. degree in material analysis from the Paris XI university in 1997, for his work in the IBM Physical analysis laboratory. He joined Alcatel CIT in 2001, where he was engaged in metal deposition processes and etching on semiconductor devices. Since 2002, he's in charge of the e-beam facility in the Alcatel Thales III-V lab. 
Frédéric Pommereau received the Doctorate degree in 1989 from Université de Paris XI (Orsay). His Ph. D thesis is on the modelling of contact lithography for the fabrication of GaAs IC's.

From 1989 to 1991, he was engaged in the fabrication of integrated circuits on silicon with MATRA MHS. He joined Alcatel Alsthom Research in 1991, and has been involved in research activities on semiconductor optical amplifiers (SOA), arrayed waveguides and SOAs, high speed photodiodes, and photonic crystals based devices. He is now responsible for technology implementation including lithography and etching on III-V semiconductors within Alcatel Thales III-V Lab.

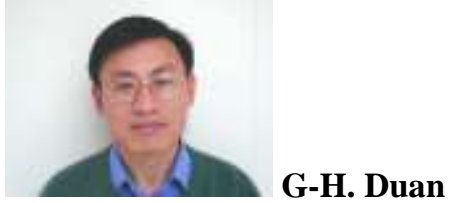

Guang-Hua Duan (S'88-M'90-SM'01) received the B. E. degree in 1983 from Xidian University, Xi'an, China, the M. E. and Doctorate degrees in 1987 and 1991 respectively, both from the Ecole Nationale Supérieure des Télécommunications (ENST), France, all in applied physics. He was habilitated to direct researches by Université de Paris-Sud in 1995.

He is now a team leader within Alcatel Thales III-V Lab, with research activities on nanophotonics (quantum dots and photonic crystals), advanced semiconductor lasers, optical amplifiers and functional optoelectronic sub-systems for core and metro networks. He is author or co-author of more than 150 research papers, 8 patents and a contributor to book chapters. He lectures in the fields of electromagnetism, optoelctronics and laser physics in ENST and in Ecole Supérieure d'Optique. Previously, he was a post-doctoral fellow supported by both Alcatel Alsthom Research and ENST from 1991 to 1992. Then, he had been an Assistant, then an Associate Professor at ENST from 1992 to 2000 . He was with the University of Maryland as a Visiting Associate Professor from 1998 to 1999. He joined Opto+, Alcatel Research \& Innovation Center in Marcoussis on October 2000. 